\title{
O PERFIL DO CLIENTE DE FUNDOS DE INVESTIMENTO MOBILIÁRIO CAIXAGEST, NA AGÊNCIA DE VISEU DA CGD
}

\author{
Sandra Rodrigues* \\ Paulo Almeida Pereira**
}

\begin{abstract}
Em consequência de um estágio curricular desenvolvido na agência de Viseu da Caixa Geral de Depósitos (CGD), foram recolhidas informações relevantes sobre toda a população de clientes com aplicações em Fundos de Investimento Mobiliário Caixagest. Este trabalho pretende apresentar os vários fundos existentes, bem como o perfil do cliente Caixagest da agência bancária em análise. São estudados todos os clientes (particulares e pessoas colectivas) deste tipo de aplicações, utilizando métodos de estatística descritiva, sendo analisadas algumas das variáveis que os definem, como por exemplo: género, idade, estado civil, local de residência, actividade profissional, se são emigrantes ou reformados. Estas variáveis são posteriormente cruzadas com os montantes totais e valores médios investidos em cada tipo de fundos, sendo ainda aplicada a técnica de análise factorial de componentes principais aos montantes aplicados por todos os clientes particulares nos vários fundos. Consegue, assim, definir-se o perfil do cliente de fundos de investimento imobiliário Caixagest na agência de Viseu da CGD.
\end{abstract}

Palavras-chave: Investimento mobiliário, fundos Caixagest, agência de Viseu da CGD, perfil do cliente, análise estatística.

* Estagiária na Caixa Geral de Depósitos.

** Instituto Universitário de Desenvolvimento e Promoção Social - Pólo de Viseu do Centro Regional das Beiras da Universidade Católica Portuguesa. 


\section{OS FUNDOS CAIXAGEST}

A Caixagest, Técnicas de Gestão de Fundos, S.A., é uma sociedade de Fundos de Participação, constituída em 6 de Novembro de 1990, tendo como objectivo principal a administração, gestão e representação de Fundos de Investimento Mobiliário, aberto ou fechado.

Em 31 de Dezembro de 1998, o capital da sociedade era constituído por 1500000 acções com valor nominal de $1000 \$ 00$, totalmente subscritas e realizadas, assim distribuídas:

\section{Quadro I}

CAPITAL SOCIAL DA CAIXAGEST (Milhões de contos)

\begin{tabular}{lcc}
\hline \multicolumn{1}{c}{ Estrutura Accionista } & Capital Social & $\%$ \\
\hline Caixa Geral de Depósitos, S.A. & 1175000 & 78,3 \\
Caisse de Dépôts et Consignations - CDC Gestion & 175000 & 11,7 \\
Caixa - Participações, SGPS, S.A. & 150000 & 10,0 \\
\hline \multicolumn{1}{c}{ TOTAL } & 1500000 & 100,0 \\
\hline
\end{tabular}

Fonte: Intranet - Caixagest.

A sociedade é detida maioritariamente pelo Grupo CGD, pelo que as decisões do Grupo são determinantes na gestão da sociedade.

O montante global das aplicações de Fundos de Investimento Mobiliário ascendia a 4,8 mil milhões de $\operatorname{contos}^{1}$ no final de 1998, correspondendo a um crescimento de $22 \%$ em relação ao ano anterior.

\section{Gráfico I}

ESTRUTURA DA CARTEIRA DOS FUNDOS CAIXAGEST

EM 31/12/98

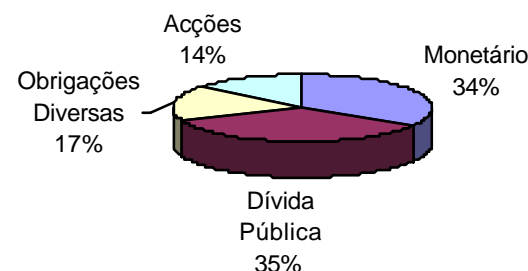

Fonte: RELATÓRIO E CONTAS - 1998, Caixagest, S.A., p. 17. 
"O montante dos fundos sob gestão da Caixagest, consolidado (expurgado do investimento dos fundos de Fundos nos outros fundos), em Dezembro de 1998, ascendia a 823 milhões de contos. Este valor representa uma quota de $22 \%$ no total de activos geridos pelos Fundos de Investimento Mobiliário"2.

A Caixagest prosseguiu uma política de diversificação da gama de produtos e dos mercados abrangidos, o que origina uma estrutura organizacional de elevada dimensão, nomeadamente no que respeita ao quadro de pessoal e meios técnicos de apoio à gestão de investimentos, encontrando-se dividida em três grandes áreas funcionais:

?Investimento - órgão responsável pela constituição e gestão de carteiras dos fundos, apoiando as decisões de investimento em estudos macro e microeconómicos executados pela análise financeira;

?Administrativa - responsável pelo departamento administrativo, valorização das carteiras e contabilidade dos fundos e da Sociedade Gestora;

??Comercial - órgão responsável pelos clientes dos fundos e pelo acompanhamento da rede de agências da Caixa Geral de Depósitos (CGD) em que são distribuídos os fundos.

\subsection{Características dos fundos caixagest}

O aforrador vulgar, após ser alertado para alternativas mais rentáveis do que os tradicionais depósitos a prazo, tem-se deparado com problemas de tempo e de conhecimento de produtos, ficando frequentemente confundido com a diversidade de opções e de ofertas múltiplas dos diversos intervenientes nos mercados financeiros. Tendo em vista resolver o problema da escolha e permitir às pequenas poupanças o acesso aos mercados, surgiram os Fundos de Investimento, que consistem num conjunto de valores recebidos de uma diversidade de aforradores, que no caso tomam a designação de participantes, valores esses entregues a um ou mais bancos (bancos depositários para este efeito) e administrados por uma sociedade gestora que tem a responsabilidade de os aplicar, segundo critérios estabelecidos nos estatutos de cada fundo.

Os fundos não têm personalidade jurídica, não oferecem rendimentos fixos e cada uma das partes do fundo é uma unidade de participação (UP), a qual vai assumindo valorizações diversas ao longo do tempo, conforme a evolução global do fundo. O cliente do Banco participa no fundo com uma determinada quantia, expressa em unidades de participação. 
Os fundos estão sujeitos a diversas qualificações, conforme os critérios a considerar. Se permitem aos participantes a entrada e a saída em qualquer data, são abertos; se não, são fechados. Conforme o objecto de aplicação seja maioritariamente constituído por valores mobiliários ou bens imobiliários, assim são denominados os fundos. Aqui pretende apenas dar-se ênfase aos Fundos de Investimentos Mobiliários Abertos, onde se situa toda a família de Fundos Caixagest. Deste modo, um fundo de investimento mobiliário consiste num conjunto de valores:

?Yesultante de um conjunto de poupanças de uma pluralidade de investidores, denominados participantes;

?Investido em instrumentos dos mercados financeiros;

?gerido de uma forma profissional por entidades especializadas, as sociedades gestoras;

?assistido administrativa e comercialmente por entidades depositárias e comercializadoras;

?3ujeito a supervisão, pelas autoridades do mercado de capitais.

Os primeiros fundos de investimento mobiliário foram criados em 17 de Dezembro de 1990, tendo sido cada vez mais diversificada, a oferta de diferentes fundos, até aos dias de hoje, de modo a aproveitar melhor a segmentação do mercado. No Quadro A.1 dos Anexos são apresentados todos os fundos Caixagest existentes (agrupados em vários tipos de fundos), bem como um resumo das suas características mais importantes.

Os fundos de investimento apresentam determinadas vantagens, como a liquidez assegurada, a isenção de determinados tipos de impostos (para certos fundos), a possibilidade de dedução no Imposto sobre o Rendimento de Pessoas Singulares (IRS), para outros e, certamente, os rendimentos concorrenciais; mas também certos custos, como comissões de subscrição e de resgate. As particularidades de cada fundo de investimento tornam-o atractivo para determinados segmentos do mercado bancário. No Quadro II apresentam-se os vários fundos de investimento mobiliário Caixagest, agrupados em tipos de fundos e os clientes-alvo a que se dirigem.

Os diferentes fundos Caixagest têm composições diversas, variando elas próprias ao longo do tempo, sendo geridos com o propósito de maximizar a sua rentabilidade. A performance e a competitividade de cada fundo, no mercado onde se insere, são avaliadas através da comparação da evolução de cada um dos fundos com os índices que medem a evolução dos mercados financeiros, usando esses como uma medida padrão (Benchmark) a seguir pelos fundos. A rentabilidade gerada por cada fundo é função das composições dos fundos e das variações do mercado ${ }^{3}$, podendo apresentar grandes flutuações, para determinados tipos de fundos, ao longo do tempo. 


\section{FUNDOS CAIXAGEST E CLIENTES ALVO}

\begin{tabular}{ll}
\hline \multicolumn{1}{c}{ FUNDO CAIXAGEST } & \multicolumn{1}{c}{ CLIENTE-ALVO } \\
\hline Fundos de Liquidez: & Particulares \\
\hline Curto Prazo & Particulares do segmento alto; entidades colectivas. \\
\hline Moeda & $\begin{array}{l}\text { Particulares do segmento médio e empresas com } \\
\text { excedentes de tesouraria. }\end{array}$ \\
\hline Tesouraria & Particulares do segmento médio e alto. \\
\hline Fundos de Aforro: & Reformados e Pensionistas. \\
\hline Rendimento & \\
\hline Renda Mensal & Particulares do segmento médio e alto. \\
\hline Fundos de Optimização: & Multivalor, Investimento \\
\hline Fundos de Valor Acrescentado: \\
\hline $\begin{array}{l}\text { Renda Acumulada e } \\
\text { Internacional }\end{array}$ & $\begin{array}{l}\text { Particulares de rendimento médio/alto que aceitam } \\
\text { um grau de risco elevado. }\end{array}$ \\
\hline Multidivisa & Particulares do segmento alto. \\
\hline Valorização & $\begin{array}{l}\text { Particulares que gostam de correr riscos, mas não } \\
\text { dominam as transacções em Bolsa. }\end{array}$ \\
\hline PPA Valorização Fiscal & $\begin{array}{l}\text { Particulares com elevada tributação, sensíveis aos } \\
\text { benefícios fiscais inerentes ao produto. }\end{array}$ \\
\hline
\end{tabular}

\subsection{Risco e rentabilidade}

Como já foi referido, existe uma relação directa entre as situações que se vivem nos mercados financeiros e as rentabilidades que se podem obter nos diferentes fundos. Essas rentabilidades são essencialmente afectadas pela evolução das taxas de juro nacionais que, por sua vez, podem ser influenciadas por factores internos ou externos à economia portuguesa. Uma subida ou descida das taxas de juro tem diferentes efeitos nos vários activos financeiros e, consequentemente, nos fundos especializados para cada tipo de activos. No campo interno, a estabilidade política nacional, o crescimento económico e a variação da inflação, são os principais influenciadores da evolução das taxas de juro nacionais.

O processo de implementação do Euro implic ou uma convergência entre os vários países da União Europeia Monetária, controlando a dívida pública, a inflação e as variações cambiais. Por sua vez, a evolução das taxas de juro nos Estados Unidos da América e, consequentemente, da taxa de câmbio de 
moedas europeias face ao dólar, é outro factor de grande importância na evolução dos mercados europeus. $\mathrm{O}$ Euro veio anular o factor de instabilidade cambial nas moedas que integram a União Europeia Monetária, reforçando o peso desta nas relações monetárias internacionais.

Quando o aforrador opta por investir num fundo, é compreensível que, numa primeira análise, todos eles lhe possam parecer semelhantes. No entanto, existem no mercado vários tipos de fundos, que procuram responder a diferentes necessidades e objectivos pessoais de cada tipo de investidor.

A procura de maiores rentabilidades, por parte do aforrador, tem criado alguma pressão nas redes comerciais que, na tentativa de cativação dos clientes, optam por aconselhar os fundos consoante as suas rentabilidades potenciais, sem levar em conta outros factores não menos importantes como a liquidez, o prazo, a volatilidade e o risco.

A rentabilidade dos fundos depende do rendimento proporcionado pelos produtos financeiros que os constituem e repercute-se no valor patrimonial das UP; caso as sociedades gestoras dos fundos de Investimento Mobiliário de médio e longo prazo (abertos ou fechados) optem por distribuir parte da valorização patrimonial do fundo pelos participantes, a título de rendimentos, isto provocará uma diminuição momentânea do valor patrimonial das UP.

A existência de comissões de subscrição e de resgate conduzem à procura de saber qual o break-even point, ou seja, qual o rendimento da UP necessário para cobrir os custos das comissões.

A Caixagest põe à disposição do aforrador uma variedade de fundos de investimento, diversificados pelos vários mercados financeiros nacionais e internacionais. Desta forma, é possível satisfazer um conjunto maior de segmentos de clientes, em termos da sua dimensão, de prazos, de investimento e da relação potencial entre risco e rentabilidade.

Pode, então, perspectivar-se a globalidade da oferta Caixagest como estando concebida e estruturada numa relação crescente entre rentabilidade e risco, representada no Gráfico II.

Num dos extremos apresentam-se os Fundos de Liquidez e de Aforro, com um risco praticamente nulo e rentabilidades médias mais baixas, enquanto no outro encontram-se os Fundos de Valor Acrescentado, com maior grau de risco mas com rentabilidades potenciais superiores. Numa posição intermédia, optimizando esta relação, estão os Fundos de Optimização.

\section{Fundos de Liquidez e Aforro}

As rentabilidades destes fundos evoluem na mesma medida das taxas de juro nacionais de curto prazo. Assim, numa conjuntura de subida destas taxas, a rentabilidade dos fundos tende também a subir, verificando a mesma 
relação, no sentido inverso. No entanto, e apesar desta ser uma relação directa, as reacções destes fundos não são imediatas, variam no tempo consoante o montante sob gestão e a maturidade média de cada carteira.

Há que notar que uma conjuntura de descida de taxas pode provocar valorizações em títulos do mercado de Obrigações e influenciar contrariamente as rentabilidades dos fundos que também aí investem. Mais uma vez a relação inversa é também verdadeira.

\section{Gráfico II \\ RISCO / RENTABILIDADE DOS FUNDOS CAIXAGEST}

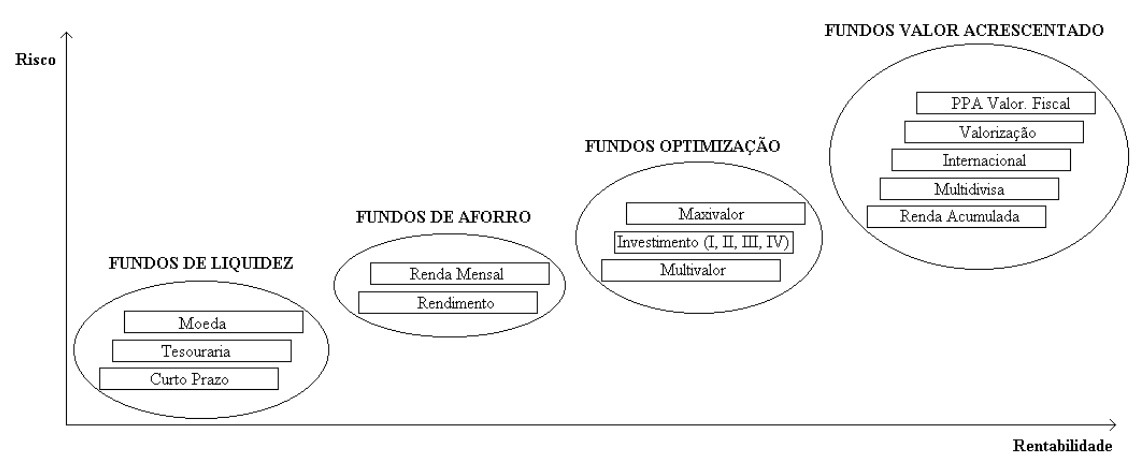

Fonte: Caixa Geral de Depósitos - Panfleto.

\section{Fundos de Valor Acrescentado}

Estes fundos tendem, em teoria, a registar um aumento das suas rentabilidades, sempre que acontece uma descida das taxas de juro, verificando-se o inverso quando numa subida de taxas. A especificidade de cada fundo confere um maior ou menor grau de relação directa com estas evoluções e, consequentemente, uma reacção diferente para cada um.

Numa conjuntura de descida das taxas de juro, os fundos que investem em Obrigações de Taxa Fixa (Renda acumulada) reagem automaticamente, valorizando o capital neles investido. Nestas Obrigações, a baixa das taxas de juro do mercado traduz-se num aumento do seu preço. Este acréscimo de rentabilidade tem como causa uma maior sensibilidade do seu preço às oscilações do nível de taxas de médio e longo prazo (até dez anos), em vigor no mercado.

\section{Fundos de Optimização}

A evolução das rentabilidades dos fundos de optimização está dependente das percentagens de investimento nos outros fundos e, consequentemente, na evolução das rentabilidades dos mesmos. Com uma gestão activa e de 
optimização de decisões de investimento, a alocação das carteiras dos Fundos Caixagest Investimento, Multivalor e Maxivalor irá aumentar ou diminuir a exposição de fundos de maior potencial, consoante as expectativas de valorização dos mesmos. No entanto, os fundos têm políticas de investimento pré-definidas que serão respeitadas e é sobre elas que, consoante as expectativas de evolução de mercados, se aumenta ou diminui a exposição aos diversos mercados.

\section{O PERFIL DO CLIENTE DOS FUNDOS CAIXAGEST NA AGÊNCIA DE VISEU DA CGD}

Após a caracterização dos fundos de investimento mobiliário Caixagest, vamos tentar definir o perfil dos seus clientes na agência de Viseu da CGD. "Não são só os traços de personalidade que induzem o indivíduo à acção, mas também factores contemporâneos ou próprios de um determinado momento (...), em outras palavras, os motivos que levaram uma pessoa a agir passam, às vezes, a constituir objecto de futuras acções do mesmo indivíduo"4.

Este estudo incide sobre os clientes, quer particulares, quer empresas, da agência de Viseu que investem na sociedade gestora - Caixagest, Técnicas de Gestão de Fundos, S.A. A análise trata a totalidade da população em causa, em que cada elemento consiste num cliente dos fundos Caixagest. Por razões de sigilo, que não o bancário, mas sim a confidencialidade comercial, apenas é possível apresentar os resultados em valores relativos, que serão suficientes para a definição do perfil em causa. Todos os dados estatísticos são, assim, analisados tendo em conta a confidencialidade, tendo sido recolhidos no decorrer do mês de Janeiro de 2000.

\subsection{Os clientes particulares}

A grande maioria $(97,5 \%)$ dos clientes de fundos Caixagest na agência de Viseu da CGD são particulares, responsáveis por 93,3\% do montante total investido neste tipo de aplicações, na agência em causa. Em primeiro lugar será efectuada a caracterização dos clientes, nomeadamente no que diz respeito à naturalidade, género, classes etárias, estado civil, local de residência domiciliária e fiscal, actividade profissional, entre outros. Seguidamente, será definida a distribuição das suas aplicações pelos vários tipos de fundos Caixagest e, finalmente, os aspectos que caracterizam os 

na agência de Viseu da CGD

clientes serão relacionados com os montantes investidos nos diversos tipos de fundos, de modo a definir um perfil de risco para os clientes.

\section{Caracterização}

Relativamente ao género e à idade, podemos observar no Gráfico III que quase dois terços dos clientes são do sexo masculino, devido talvez ao facto de grande parte das aplicações familiares ainda terem como primeiro titular o "chefe de família". A classe etária dos 45 aos 64 anos engloba quase metade dos clientes, tendo as duas classes seguintes (de 25 a 44 anos e 65 anos ou mais) um número aproximado de clientes, existindo muito poucos clientes com menos de 25 anos. As disponibilidades financeiras surgem, como é óbvio, à medida que ocorre progressão na vida, sendo maiores a partir dos 45 anos de idade. Cruzando estas duas variáveis, nas várias classes etárias observa-se uma repartição, de certa forma, homogénea entre os dois sexos, excepto para a classe etária mais baixa, em que os clientes de fundos Caixagest estão repartidos equitativamente por ambos os sexos, parecendo confirmar que na constituição do agregado familiar opta-se mais pela indicação da pessoa do sexo masculino como titular das aplicações.

\section{Gráfico III}

GÉNERO E IDADE
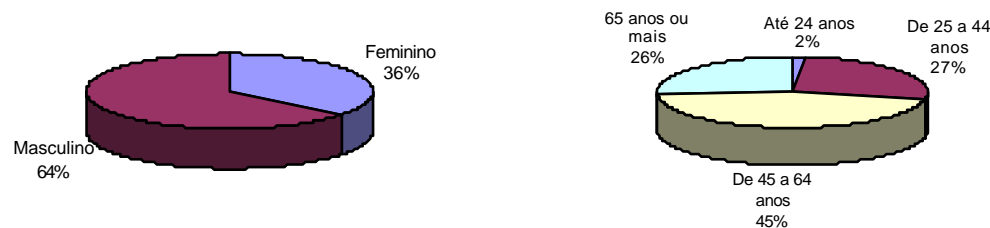

Dos clientes Caixagest, $95,5 \%$ apresentam naturalidade portuguesa, $92,5 \%$ são residentes no território nacional e 7,6\% são emigrantes. Há, ainda assim, alguns clientes estrangeiros e outros não residentes, sendo estes, quase na sua totalidade, emigrantes.

Passando para o estudo de outras variáveis, relativamente à situação de pensionista, existe uma grande percentagem de dados omissos: dos valores observáveis, $18,6 \%$ dos clientes são reformados, embora nos pareça que a frequência relativa destes clientes seja, na realidade, superior, pela comparação com a percentagem de clientes com 65 anos ou mais. Analisando o estado civil dos clientes Caixagest, verifica-se que 74,8\% são casados, $17,5 \%$ são solteiros, existindo ainda $5,8 \%$ de viúvos e $1,9 \%$ de divorciados. Nota-se também que $3,1 \%$ dos clientes são funcionários da CGD. 
Quanto à residência, estão disponíveis dados sobre o domicílio e a residência fiscal. Sobre estes últimos, há 10,0\% de dados omissos, pelo que optámos por analisar, no Gráfico IV, a residência domiciliar, por grandes áreas geográficas. A classe Distrito de Viseu diz respeito a residentes dentro do distrito, mas fora do Concelho de Viseu.

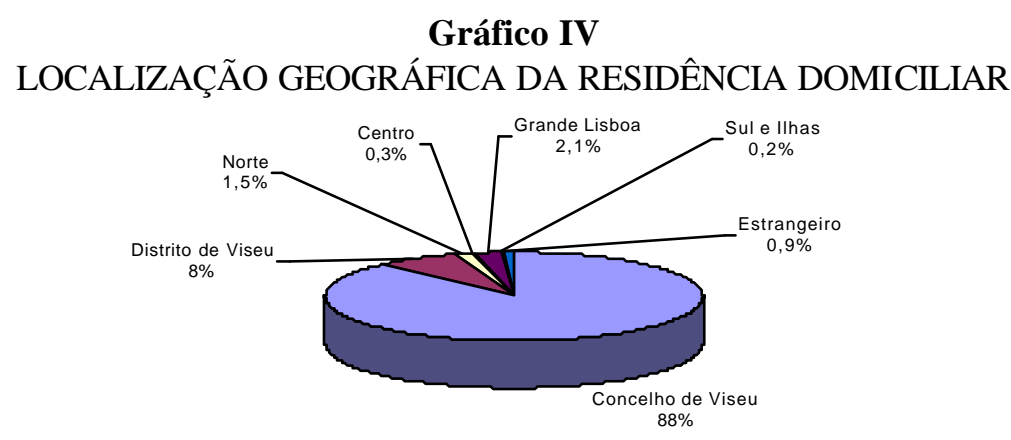

Como seria de esperar, a grande maioria dos clientes (88\%) reside no concelho de Viseu e 8\% têm ainda domicílio no distrito, estando os restantes distribuídos pelo resto do país e pelo estrangeiro.

Para terminar a caracterização dos clientes Caixagest, apresenta-se, no Gráfico V, a sua distribuição por actividade profissional, de acordo com os grupos principais definidos na Classificação Nacional de Profissões (CNP1994), elaborada em 1994, pelo Instituto de Emprego e Formação Profissional (IEFP, 1994).

\section{Gráfico V}

ACTIVIDADE PROFISSIONAL DE ACORDO COM A CNP-1994

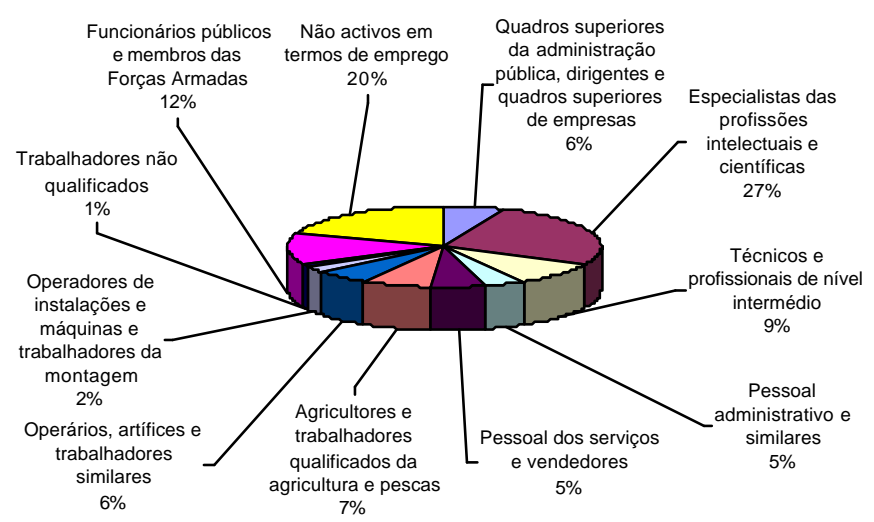



na agência de Viseu da CGD

Esta classificação é apresentada no Quadro A.2 dos Anexos para as profissões exercidas pelos clientes Caixagest. Os grupos com maior peso relativo são os 'Especialistas das profissões ntelectuais e científicas" e, talvez inesperadamente, os clientes "Inactivos, em termos de emprego". Destacam-se ainda os grupos constituídos pelos "Funcionários públicos e membros das Forças Armadas" e os "Técnicos e profissionais de nível intermédio".

Após uma análise das semelhanças entre os vários grupos definidos de acordo com a CNP-1994, relativamente à afinidade entre as profissões e a diversas outras variáveis, entre elas, o sexo, a idade, o local de residência e os montantes médios investidos nos vários tipos de fundos, optámos por reclassificar as profissões em seis classes (de $A$ a $F$ ), de modo a facilitar posteriores análises, de acordo com o Quadro III, cuja caracterização é ilustrada pelo Gráfico VI.

Quadro III

AGRUPAMENTO DAS PROFISSÕES DOS CLIENTES CAIXAGEST

A - Quadros superiores:

1: Quadros superiores da admin. pública, dirigentes e quadros sup. de empresas

B - Profissões intelectuais e técnicos:

2: Especialistas das profissões intelectuais e científicas

3: Técnicos e profissionais de nível intermédio

C - Pessoal administrativo e de serviços:

4: Pessoal administrativo e similares

5: Pessoal dos serviços e vendedores

D - Agricultores, operários e não qualificados:

6: Agricultores e trabalhadores qualificados da agricultura e pescas

7: Operários, artífices e trabalhadores similares

8: Operadores de instalações e máquinas e trabalhadores da montagem

9: Trabalhadores não qualificados

E- Func. públicos e Forças Armadas:

10: Funcionários públicos e membros das Forças Armadas

\section{F - Não activos:}

11: Não activos em termos de emprego

Podemos, desde já, observar as diferenças que caracterizam, à partida, as várias classes de profissões definidas, no que respeita à sua contribuição para o número de clientes Caixagest, ao sexo, idade e local de residência.

Os maiores grupos de clientes são os das "Profissões intelectuais e técnicos", seguido pelos "Não activos". Nestas duas classes, o sexo feminino apresenta um peso superior ao que tem nas restantes (com 
particular incidência nos "Não activos"), o mesmo sucedendo com as classes etárias inferiores a 45 anos. As idades superiores a 65 anos predominam nos "Quadros superiores", "Agricultores, Operários e não Qualificados" e nos "Não activos". Não se observam grandes diferenças quanto às zonas de domicílio dos vários grupos.

\section{Gráfico VI}

\section{CARACTERIZAÇÃO DOS GRUPOS DE CLIENTES CAIXAGEST}
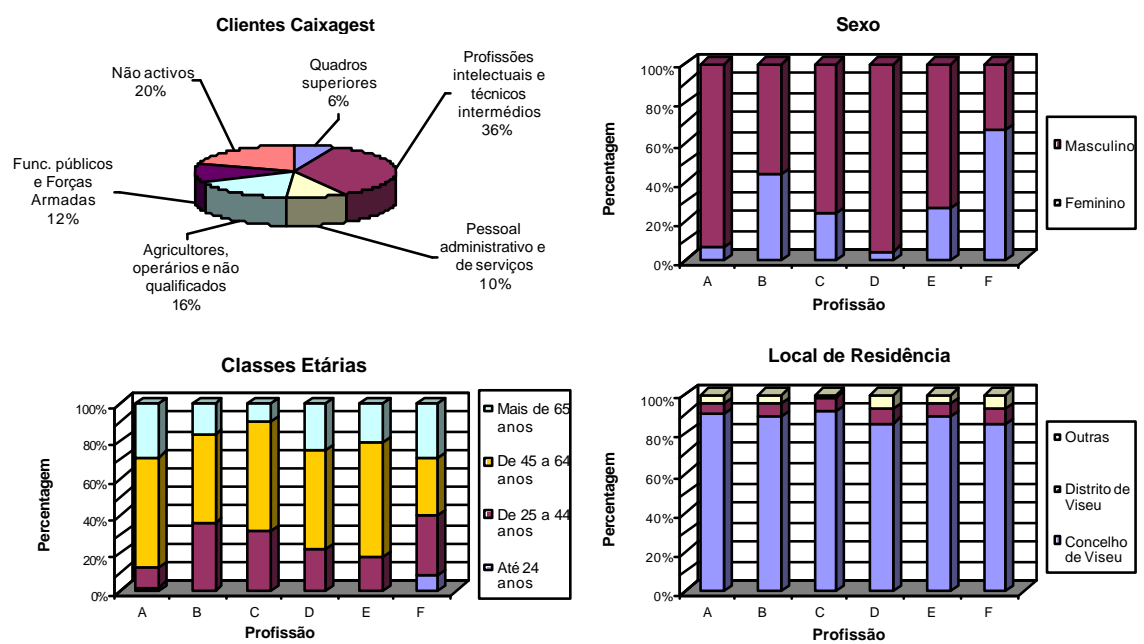
A - Quadros superiores
B - Profissões intelectuais e técnicos
C - Pessoal administrativo e de serviços

D - Agricultores, operários e não qualificados

E - Func. públicos e Forças Armadas

F - Não activos

\section{Distribuição das aplicações pelos fundos Caixagest}

Os clientes distribuem as suas aplicações pelos vários tipos de fundos existentes, como se pode verificar pelo Gráfico VII, sendo os fundos de liquidez e de aforro os preferidos, certamente pelo pequeno risco que comportam e pela elevada liquidez; verificando-se que os montantes totais aplicados pelos clientes são distribuídos, por ordem decrescente, pelos fundos de menor risco e rentabilidade para os que comportam maior risco, mas potencialmente maior rentabilidade.

No Quadro IV procede-se à desagregação dos montantes totais aplicados por todos os fundos Caixagest. Nos fundos de liquidez e de aforro, as preferências dos investidores vão claramente para os fundos Caixagest Tesouraria e Rendimento, respectivamente, enquanto que nas restantes famílias de fundos as aplicações estão mais distribuídas, com especial 
O perfil do cliente de fundos de investimento mobiliário Caixagest, na agência de Viseu da CGD

relevância para os fundos Caixagest Multivalor, Investimento IV, Valorização e PPA Valorização Fiscal.

\section{Gráfico VII}

APLICAÇÕES POR TIPOS DE FUNDOS CAIXAGEST

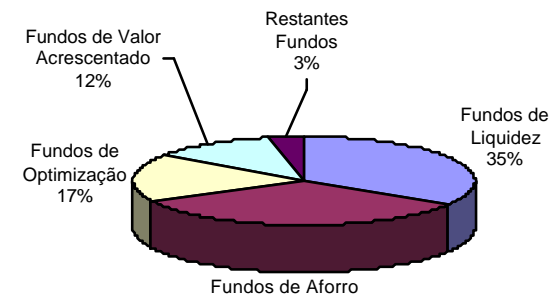

$33 \%$

Quadro IV

DESAGREGAÇÃO DAS APLICAÇÕES POR FUNDOS CAIXAGEST

\begin{tabular}{llrr}
\hline \multicolumn{1}{c}{ Tipo de fundo } & \multicolumn{2}{c}{ Fundo Caixagest } \\
\hline Fundos de Liquidez & $34,1 \%$ & Curto Prazo & $9,0 \%$ \\
& & Tesouraria & $25,1 \%$ \\
& & Moeda & $0,0 \%$ \\
\hline Fundos de Aforro & $33,4 \%$ & Rendimento & $33,2 \%$ \\
& & Renda Mensal & $0,2 \%$ \\
\hline Fundos de Optimização & $17,1 \%$ & Multivalor & $6,1 \%$ \\
& & Investimento I & $2,3 \%$ \\
& & Investimento II & $1,0 \%$ \\
& & Investimento III & $1,8 \%$ \\
& & Investimento IV & $5,5 \%$ \\
& & Maxivalor & $0,4 \%$ \\
\hline Fundos de Valor Acrescentado & $12,1 \%$ & Renda Acumulada & $1,5 \%$ \\
& & Multidivisa & $0,0 \%$ \\
& & Internacional & $0,3 \%$ \\
& & Valorização & $6,4 \%$ \\
\hline Restantes Fundos & PPA Valorização Fiscal & $4,0 \%$ \\
\hline
\end{tabular}

Perfil do cliente particular de fundos Caixagest 
A análise seguinte incidirá particularmente sobre determinadas características do cliente, definidas pelas variáveis sexo, classe etária, local de residência e actividade profissional e o seu cruzamento com os montantes investidos em cada um dos tipos de fundos Caixagest existentes e consequente relação entre estas variáveis. Existem várias opções quanto à forma de aprofundar este estudo, mas estamos perante um conjunto singular de limitações: é importante manter o sigilo relativamente à apresentação de valores absolutos; os dados resultam da globalidade da população em análise e não de uma amostra e, além disso, os montantes investidos em cada tipo de fundo apresentam uma distribuição bastante assimétrica positiva ou enviesada à esquerda, pelo que não se deve efectuar uma análise identificando e eliminando os outliers (casos extremos influentes), pois "A eliminação de um potencial outlier é imprópria quando a variável tem uma distribuição com caudas pesadas, no quadro da qual os outliers são naturais ... a política mais prudente é isolar alguns valores para lhe prestar ou pedir que lhes seja prestada atenção especial" ${ }^{5}$.

Para levar a cabo esta análise, vamos dividir a população em dois grupos: o primeiro constituído pelos clientes acima do percentil de $95 \%$, no que diz respeito ao montante total investido, ou seja, 5\% dos clientes que têm maiores aplicações em Fundos Caixagest na agência de Viseu; e, o segundo, que integra os restantes $95 \%$ dos clientes. Estes dois grupos são, inicialmente, caracterizados e de seguida estudam-se as distribuições dos montantes investidos por várias classes, bem como os valores médios aplicados por cada uma dessas classes, com o objectivo de simplificar a apresentação dos resultados. Estes valores médios são apresentados num índice referenciado ao montante total máximo investido por um único cliente particular, a que atribuímos o índice 1000.

\section{Grupo TOP 5\% de clientes}

Este grupo de 5\% dos clientes integra aqueles com maiores montantes investidos em Caixagest, responsáveis por 35,9\% do total investido, por clientes particulares, neste tipo de fundos, na agência de Viseu.

Neste grupo, $72 \%$ dos clientes são do sexo masculino e $28 \%$ do sexo feminino; quanto às classes etárias: $40 \%$ têm 65 anos ou mais, outros $40 \%$ estão entre 45 e 64 anos e os restantes $20 \%$ apresentam entre 25 e 44 anos; $16 \%$ são emigrantes; $8 \%$ são reformados; a residência de $91 \%$ destes clientes é no concelho de Viseu, 5\% no distrito de Viseu e os restantes no resto do país e, no que concerne às actividades profissionais previamente definidas, a distribuição é feita de acordo com o Gráfico VIII.

Relativamente à totalidade dos clientes, neste grupo temos um maior peso dos clientes do sexo masculino, da classe etária com mais que 65 anos, dos emigrantes e, relativamente às profissões, das classes A (Quadros 20 
Superiores) e B (Profissões Intelectuais e Técnicos), observando-se ainda um menor peso dos reformados.

De modo a verificar se a distribuição dos montantes investidos é idêntica à distribuição dos clientes, apresentamos o Gráfico IX, que compara a frequência relativa dos clientes em cada uma das classes das variáveis analisadas, com a dispersão do montante total investido pelas mesmas classes: apenas se observam diferenças relevantes no que diz respeito às classes de actividades profissionais, mais significativas na A (Quadros Superiores), em que o peso dos montantes aplicados por esta classe é superior à sua frequência relativa, em número de clientes e na classe $\mathrm{B}$ (Profissões Intelectuais e Técnicos), em que ocorre a situação inversa.

\section{Gráfico VIII}

\section{PROFISSÕES DOS MAIORES CLIENTES (Grupo TOP 5\%)}

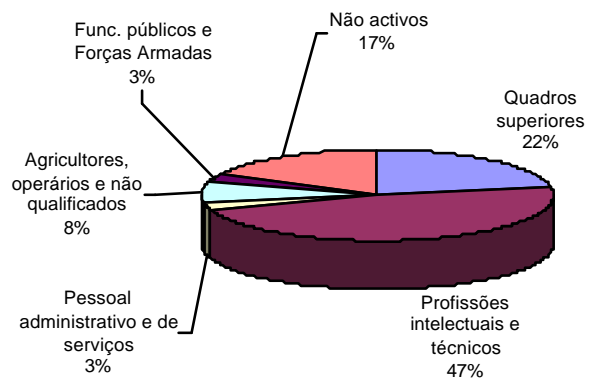




\section{Gráfico IX}

COMPARAÇÃO ENTRE OS MONTANTES INVESTIDOS E O NÚMERO DE CLIENTES (Grupo TOP 5\%)
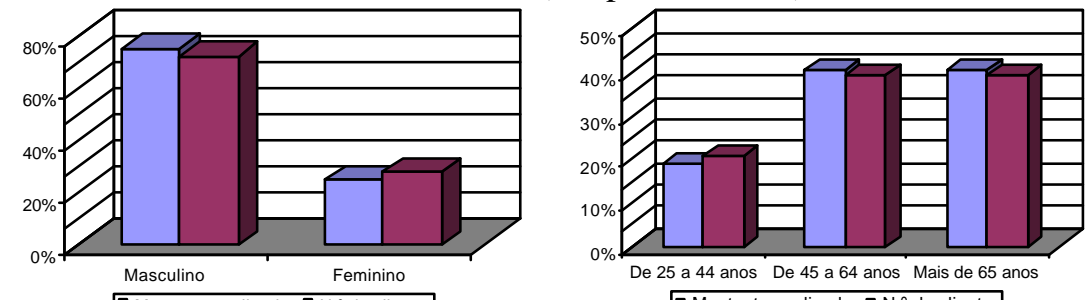

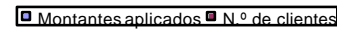
口 Montantes aplicados $\mathbf{\square}$ N. ${ }^{\circ}$ de clientes
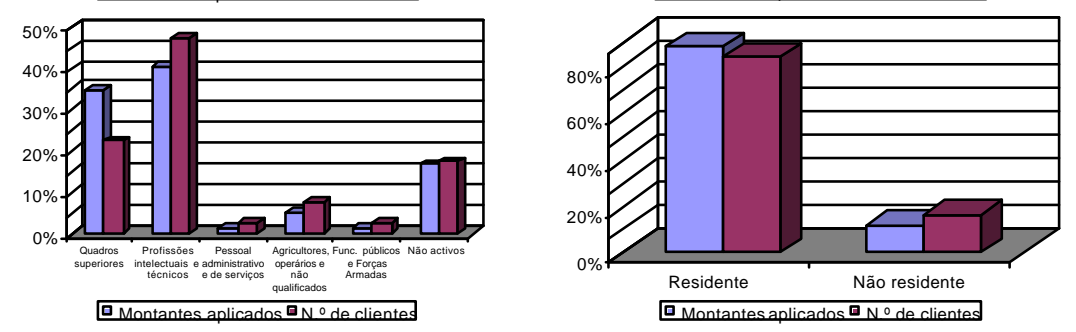

No que diz respeito à distribuição dos montantes aplicados por este grupo de clientes pelos vários fundos, podemos observar no Gráfico $\mathrm{X}$ que, relativamente à totalidade dos clientes, os fundos de Liquidez e, principalmente, os fundos de Aforro perdem peso relativo, enquanto os restantes fundos aumentam a sua contribuição relativa para o total aplicado, com especial incidência nos fundos de Optimização, ou seja, há transferência do peso relativo dos fundos com menor risco e potencial rentabilidade, embora continuem a ter uma posição dominante, para os fundos de maior risco, mas com uma maior perspectiva de rentabilidade. 


\section{Gráfico X}

APLICAÇÕES POR TIPOS DE FUNDOS CAIXAGEST (Grupo TOP 5\%)

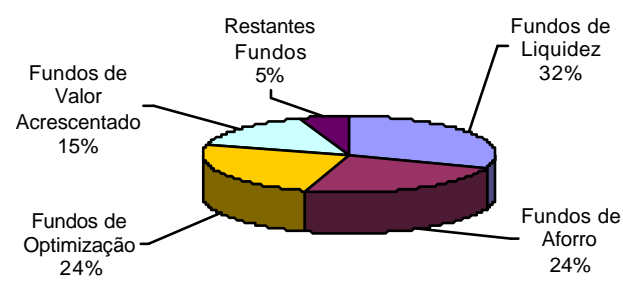

O Gráfico XI ilustra a forma como se podem caracterizar os clientes deste grupo, em função dos montantes investidos nos vários tipos de fundos. Relativamente ao sexo, os clientes do sexo feminino distribuem as suas aplicações mais pelos fundos de Aforro e de Valor Acrescentado, quando comparados com os do sexo oposto, que dão maior peso relativo às aplicações nos restantes tipos de fundos. Analisando as preferências relativamente às classes etárias, os clientes mais jovens preferem os fundos de Optimização, enquanto que aqueles com idades superiores aplicam mais as suas poupanças nos fundos de Liquidez, de Valor Acrescentado e nos restantes fundos.

Quanto às classes de actividades profissionais definidas, a classe E (Funcionários Públicos e Força Armadas) apenas tem subscritos fundos de Liquidez e a C (Pessoal Administrativo e de Serviços) apenas tem fundos de Aforro, ambos de baixo risco. No que diz respeito às restantes, as classes $\mathrm{A}$ (Quadros Superiores) e B (Profissões Intelectuais e Técnicos) distribuem as suas aplicações, preferencialmente, pelos fundos de Liquidez, Optimização e Valor Acrescentado, a classe D (Agricultores, Operários e não Qualificados) prefere fundos de Aforro e de Optimização e a classe F (Não Activos) dá um grande peso aos fundos de Aforro. Finalmente, os não residentes em território nacional preferem subscrever fundos de Optimização e os Restantes fundos, quando comparados com os residentes em Portugal. 


\section{Gráfico XI \\ CARACTERIZAÇÃO DOS CLIENTES DE ACORDO COM A DISTRIBUIÇÃO DOS MONTANTES INVESTIDOS POR TIPOS DE FUNDOS CAIXAGEST (Grupo TOP 5\%)}
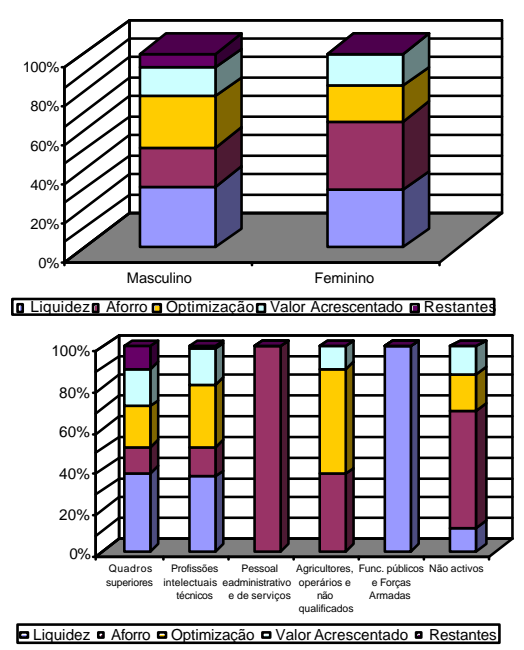
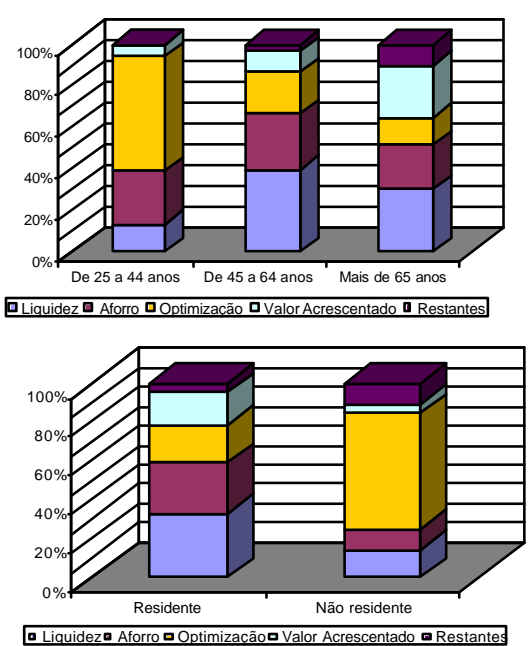

Para concluir a análise deste grupo de clientes, importa definir, no Gráfico XII, os montantes médios aplicados em cada um dos tipos de fundos. Para obviar à questão da impossibilidade da representação dos dados em valores absolutos, optou-se pela representação através de um índice, em que se atribui o índice 1000 ao montante total máximo investido por um só cliente particular e se representam os valores médios investidos por cada grupo de clientes em função desse índice.

Relativamente ao género, os clientes do sexo masculino têm maiores montantes médios em fundos de Liquidez e Optimização, enquanto que os do sexo oposto apresentam valores máximos para os fundos de Aforro e de Liquidez. Quanto às classes etárias, na mais jovem, os valores são mais elevados para os fundos de Optimização, seguidos pelos de Aforro, na intermédia, os valores médios são maiores para os fundos de Liquidez, diminuindo à medida que os fundos comportam mais riscos, nas idades superiores, os valores são mais homogéneos. Nas actividades profissionais, os valores são superiores para os fundos de Liquidez, seguidos pelos de Optimização e Valor Acrescentado na classe A, para os fundos de Liquidez e Optimização na classe B, para os fundos de Optimização na classe D e para os de Aforro na classe $\mathrm{F}$, enquanto que nas classes $\mathrm{C}$ e $\mathrm{E}$ os montantes médios são elevados para os fundos de Aforro e de Liquidez, 
respectivamente. No que respeita aos residentes o padrão segue a diminuição para fundos de maior risco e os não residentes têm valores elevados nos fundos de Optimização.

\section{Gráfico XII \\ MONTANTES MÉDIOS APLICADOS PELOS CLIENTES EM CADA TIPO DE FUNDOS CAIXAGEST (Grupo TOP 5\%)}
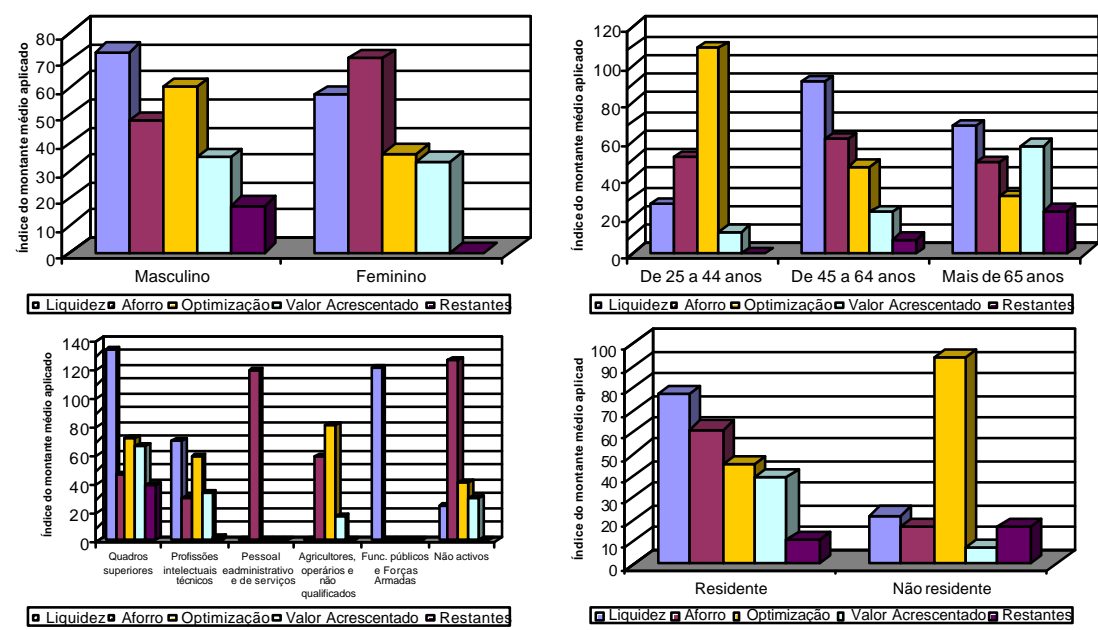

\section{Grupo dos restantes $95 \%$ de clientes}

A metodologia de análise deste núcleo de clientes será similar à realizada anteriormente. Estes restantes $95 \%$ de clientes integram aqueles com montantes investidos de dimensão inferior, que constituem $64,1 \%$ do total de aplicações, de clientes particulares, em fundos Caixagest, na agência de Viseu.

Este grupo de clientes caracteriza-se por: $64 \%$ dos clientes são do sexo masculino e $36 \%$ do sexo feminino; $46 \%$ têm entre 45 e 64 anos, $27 \%$ entre 25 e 44 anos, $25 \%$ apresentam 65 anos ou mais e $2 \%$ têm idades inferiores a 25 anos; 7\% são emigrantes; $19 \%$ são reformados; a residência de $87 \%$ é no concelho de Viseu, $8 \%$ ainda no distrito de Viseu e os restantes no resto do país, sendo a distribuição das actividades profissionais idêntica à apresentada no Gráfico VI. Este grupo, pela sua grande dimensão, apresenta características em tudo idênticas às da totalidade dos clientes.

No Gráfico XIII podemos analisar a relação, em valores relativos, entre o número de clientes e os montantes investidos, para várias classes das variáveis estudadas: o peso dos montantes investidos é superior ao do número de clientes para o sexo masculino, para idades superiores a 45 anos, 
para os Quadros Superiores e Profissões Intelectuais e Técnicos e para os não residentes, logo os montantes médios investidos por estes segmentos de clientes são superiores.

\section{Gráfico XIII \\ COMPARAÇÃO ENTRE OS MONTANTES INVESTIDOS E O NÚMERO \\ DE CLIENTES (Grupo dos restantes 95\%)}

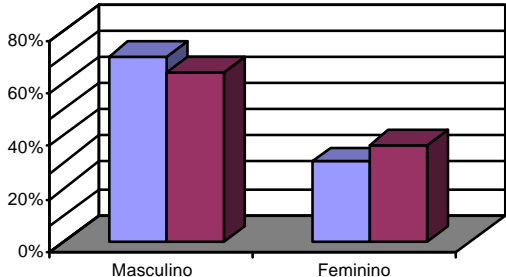

回 Montantes aplicados $\square \mathrm{N} .{ }^{\circ}$ de clientes

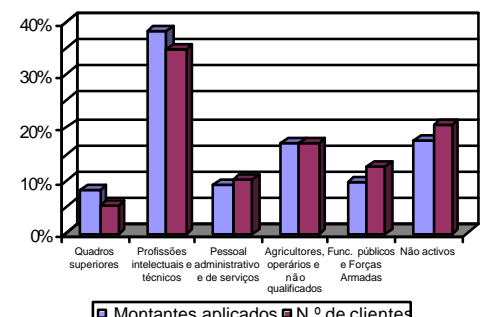

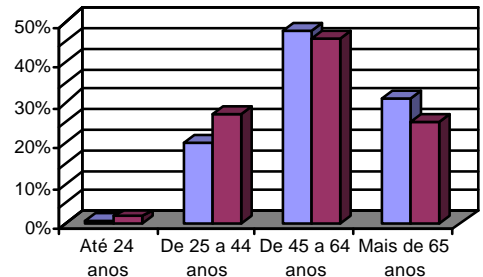

anos anos anos

口 Montantes aplicados $\square \mathrm{N} .{ }^{\circ}$ de clientes

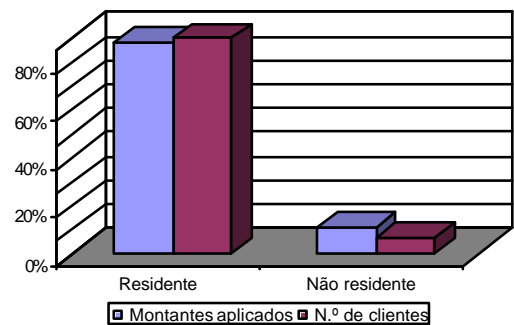

O Gráfico XIV mostra a distribuição dos montantes aplicados pelos vários fundos, ilustrando um aumento relativo dos fundos de Liquidez e de Aforro, e diminuição dos outros, relativamente à totalidade dos clientes. Ocorre um reforço da posição dos fundos de menor risco.

O Gráfico XV pretende demonstrar a caracterização dos clientes deste segundo grupo, no que respeita ao peso relativo dos montantes investidos nos vários tipos de fundos. Nota-se um maior peso dos fundos de Valor Acrescentado e menor dos fundos de Aforro nos clientes do sexo feminino. Das classes etárias mais jovens para as mais idosas, verifica-se a diminuição do peso dos fundos de Liquidez, de Optimização e de Valor Acrescentado e o aumento dos de Aforro e Restantes. Relativamente às classes profissionais, os fundos de Liquidez têm maior peso nas classes E, A e B, os fundos de Aforro nas classes D e F, os fundos de Optimização na classe D e os fundos de Valor Acrescentado nas classes C, B e E. Os residentes em território nacional preferem subscrever fundos de Liquidez e de Aforro e os não residentes dão maior peso aos fundos de Optimização. 


\section{Gráfico XIV}

APLICAÇÕES POR TIPOS DE FUNDOS (Grupo dos restantes 95\%)

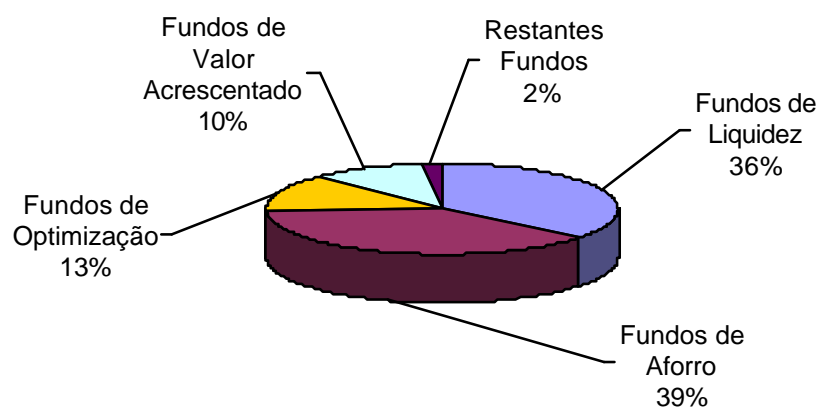

\section{Gráfico XV \\ CARACTERIZAÇÃO DOS CLIENTES DE ACORDO COM A DISTRIBUIÇÃO DOS MONTANTES INVESTIDOS POR TIPOS DE FUNDOS CAIXAGEST (Grupo dos restantes 95\%)}
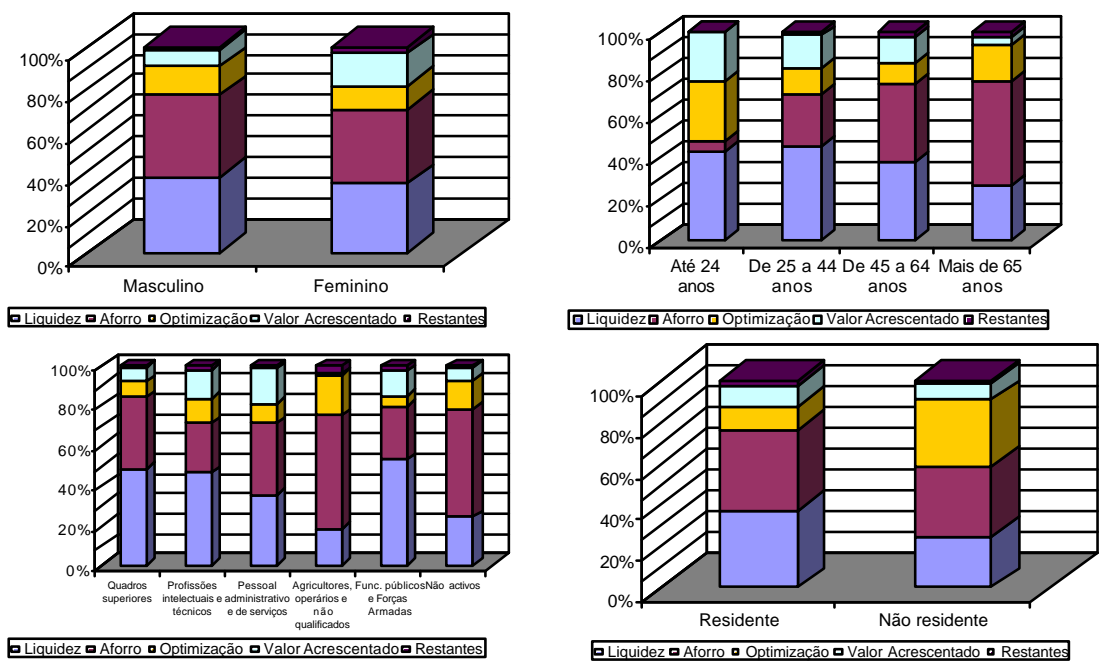

No Gráfico XVI ilustram-se os montantes médios aplicados nos vários tipos de fundos, através do índice já atrás referido. Note-se as diferenças substanciais relativamente ao grupo anterior, sendo os montantes médios aplicados bastante inferiores no grupo presentemente em estudo.

A repartição relativamente ao género é idêntica, embora os valores médios sejam inferiores para o sexo feminino. As classes etárias mais 
elevadas apresentam, relativamente a esta variável, valores genericamente superiores, sendo o aumento para classes etárias superiores mais evidente nos fundos de Aforro; a excepção observa-se para os fundos de Valor Acrescentado. Nas classes profissionais, os valores são mais elevados nas classes A e B, para os fundos de Liquidez e de Aforro, com excepção das classes D e F, que apresentam valores elevados neste último tipo de fundos, apresentando os outros fundos variações pontuais, significativas nalguns casos, para as várias classes. Os não residentes apresentam, de modo geral, montantes médios superiores, diferença ainda mais evidente nos fundos de Optimização.

\section{Gráfico XVI}

MONTANTES MÉDIOS APLICADOS PELOS CLIENTES EM CADA

TIPO DE FUNDOS CAIXAGEST (Grupo dos restantes 95\%)
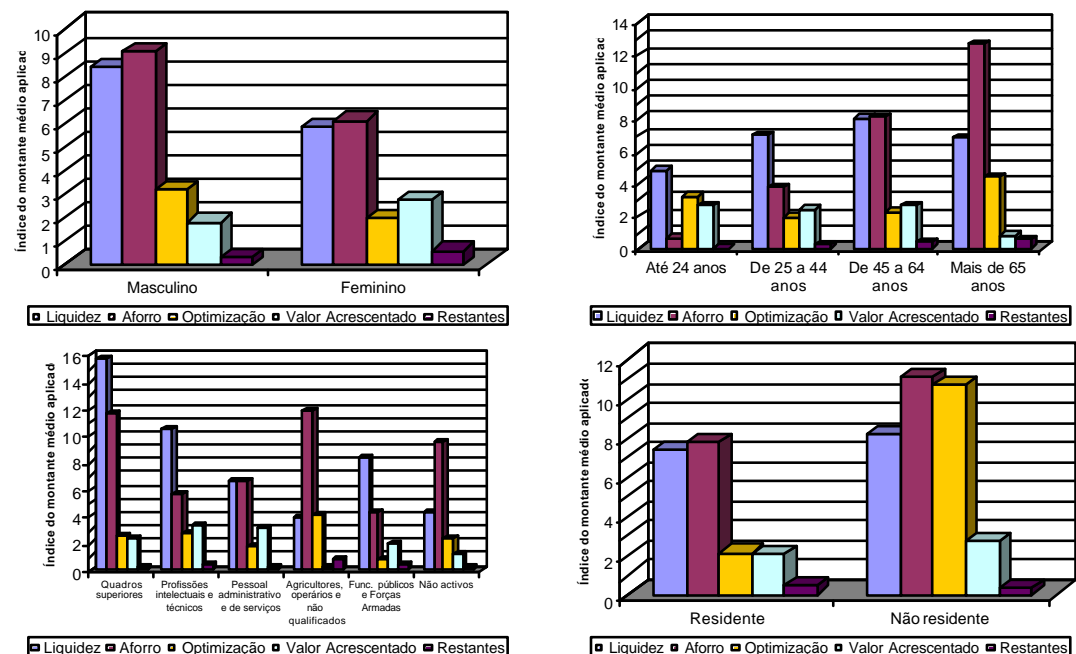

\subsection{Os clientes empresas}

Este tipo de clientes (pessoas colectivas) de fundos Caixagest constitui $2,5 \%$ do número total de clientes, sendo responsáveis por $6,7 \%$ do total 
investido nestas aplicações, na agência de Viseu da CGD. Em primeiro lugar vamos caracterizar estas empresas.

\section{Caracterização das empresas}

Todas as empresas em análise estão sediadas no concelho de Viseu, com excepção de uma única, que tem a sua sede no concelho de Tondela. Quanto ao regime jurídico, é de salientar que metade das empresas são instituições sem fins lucrativos, $22 \%$ são associações de condomínios, religiosas ou outras, $14 \%$ são sociedades por quotas e os restantes $14 \%$ pertencem à administração local. Quanto à data de constituição, $31 \%$ das empresas foram criadas nos últimos dez anos e as restantes são mais antigas, investindo todas elas em fundos Caixagest há pelo menos cinco anos. Finalmente, para definir o sector de actividade em que elas estão integradas, utilizou-se a Classificação Portuguesa das Actividades Económicas (CAE - Rev. 2), estando as empresas todas integradas em oito secções, conforme se pode verificar no Quadro A.3 dos Anexos. No Gráfico XVII podemos verificar a forma dessa distribuição, sendo apresentada como designação de algumas secções o grupo de que fazem parte as empresas dessa secção. Este gráfico ilustra também o agrupamento das empresas por sectores, sendo o sector terciário aquele com maior peso (80\%), tendo ambos os sectores primário e secundário a mesma frequência relativa (10\%).

\section{Gráfico XVII}

SECTOR DE ACTIVIDADE DAS EMPRESAS (CAE - Rev. 2)
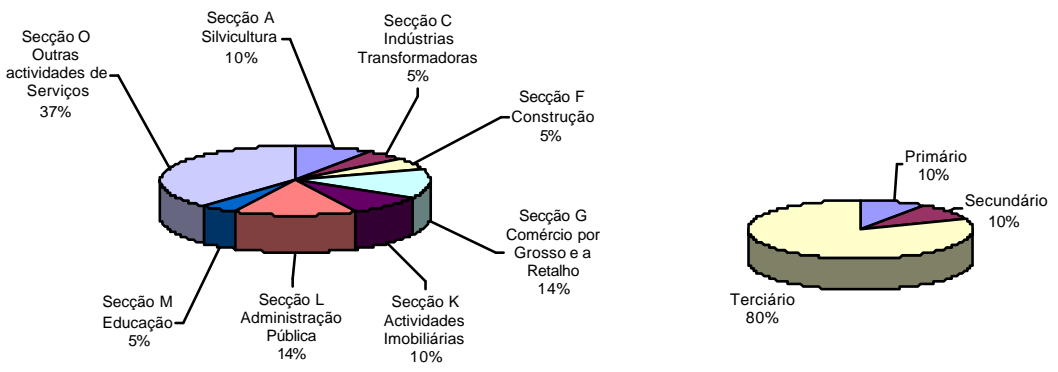

Distribuição das aplicações pelos fundos Caixagest

O Quadro V mostra a forma como estes clientes distribuem as suas aplicações pelos vários fundos Caixagest. Os fundos não apresentados na tabela não são escolhidos pelas empresas. 
Quadro V

DESAGREGAÇÃO DAS APLICAÇÕES POR FUNDOS CAIXAGEST

\begin{tabular}{lrlr}
\hline \multicolumn{1}{c}{ Tipo de fundo } & \multicolumn{2}{c}{ Fundo Caixagest } \\
\hline Fundos de Liquidez & $99,0 \%$ & Curto Prazo & $2,4 \%$ \\
& & Tesouraria & $51,0 \%$ \\
& & Moeda & $45,6 \%$ \\
\hline Fundos de Aforro & $0,5 \%$ & Rendimento & $0,5 \%$ \\
\hline Fundos de Valor Acrescentado & $0,5 \%$ & Valorização & $0,5 \%$ \\
\hline TOTAL & $100,0 \%$ & & $100,0 \%$ \\
\hline
\end{tabular}

O perfil de aplicações das empresas passa, quase na totalidade, por fundos de Liquidez, com especial relevância para os fundos Tesouraria e Moeda, fundos de elevada liquidez, resultantes certamente de aplicações de excedentes de tesouraria das empresas.

\section{Perfil do cliente empresa de fundos Caixagest}

Antes da definição do perfil, cuja análise incide exclusivamente sobre as variáveis regime jurídico e classificação das actividades económicas, importa salientar que 9\% das empresas são responsáveis por 64\% do montante total aplicado pelas pessoas colectivas nos fundos Caixagest.

No Gráfico XVIII apresenta-se a distribuição dos valores aplicados pelos vários tipos de regimes jurídicos e pelos sectores de actividade.

\section{Gráfico XVIII \\ DISTRIBUIÇÃO DAS APLICAÇÕES DAS EMPRESAS PELOS REGIMES JURÍDICOS E SECTORES DE ACTIVIDADE (CAE - Rev. 2)}
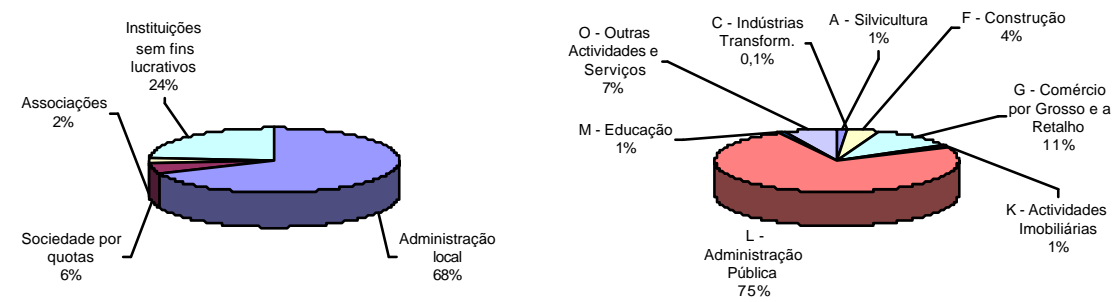

Quanto ao regime jurídico, a administração local é responsável por $68 \%$ das aplicações em fundos Caixagest, seguida pelas instituições sem fins lucrativos. No que diz respeito ao sector de actividade, a Administração Pública é responsável por $75 \%$ do investimento, sendo seguida pelo sector 

na agência de Viseu da CGD

do Comércio a Grosso e a Retalho, pelas Outras Actividades e Serviços e pelo sector da Construção, tendo os restantes sectores valores residuais.

Passando para a análise da desagregação dos investimentos pelos vários tipos de fundos, as aplicações em fundos de aforro são feitas por associações e instituições sem fins lucrativos, todas elas pertencentes à secção denominada por Outras Actividades e Serviços. Quanto aos fundos de liquidez, podemos observar no Gráfico XIX a distribuição dos montantes investidos por cada fundo e pelo total deste tipo de fundos, com excepção do Caixagest Moeda, em que a totalidade investida provém da administração local (segundo o regime jurídico) e da secção L - Administração Pública.

Segundo os regimes jurídicos, as aplicações em fundos de Curto Prazo têm um grande peso das instituições sem fins lucrativos e os fundos de Tesouraria distribuem-se, em grande parte, por estas últimas e pela Administração Local. Quanto aos sectores de actividade, nos fundos de Curto Prazo, a maioria do investimento é feito por empresas de Outras Actividades e Serviços, enquanto que nos fundos de Tesouraria, o maior peso é da Administração Pública, seguida pelo Comércio a Grosso e a Retalho.

\section{Gráfico XIX \\ DISTRIBUIÇÃO DAS APLICAÇÕES DAS EMPRESAS EM FUNDOS DE LIQUIDEZ}
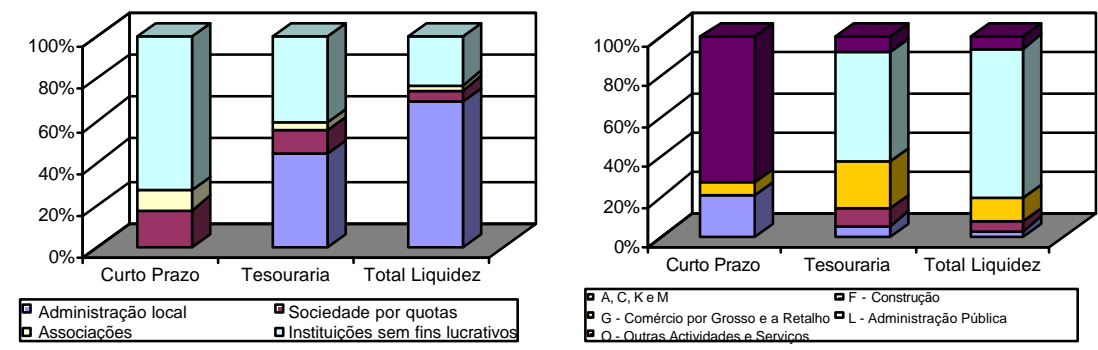

A, C, K e M - Silvicultura, Indústrias Transformadoras, Actividades Imobiliárias, Educação

Quanto aos montantes investidos pelas pessoas colectivas, eles apresentam uma grande dispersão, tendo um valor de 433,7 para a administração local, de acordo com o regime jurídico e de 448,9 para a administração pública, segundo a secção de actividade, valores medidos no mesmo índice apresentado anteriormente para os clientes particulares. No Gráfico XX apresentam-se os montantes médios aplicados para as restantes classes definidas. 


\section{Gráfico XX \\ MONTANTES MÉDIOS APLICADOS PELAS EMPRESAS \\ EM FUNDOS CAIXAGEST}
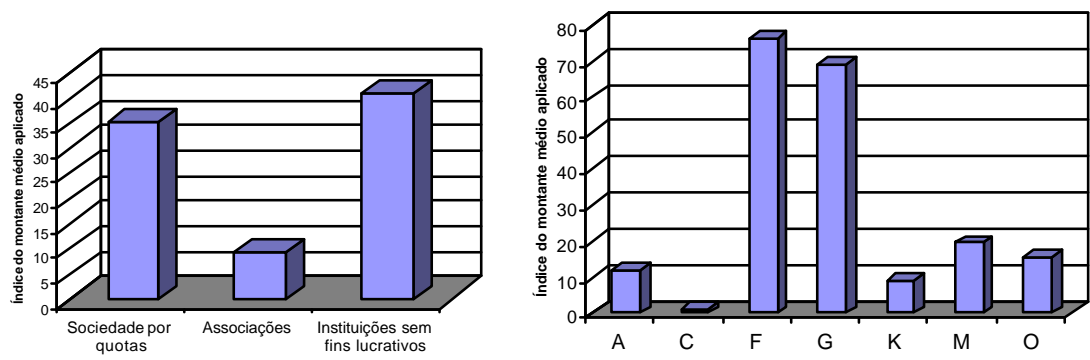

A - Silvicultura; C - Indústrias Transformadoras; F - Construção; G - Comércio por Grosso e a Retalho; K - Actividades Imobiliárias; L - Administração Pública; M - Educação; O - Outras Activid. e Serviços

Estes valores são mais elevados para as instituições sem fins lucrativos e sociedades por quotas e para os sectores da Construção e do Comércio por Grosso e a Retalho.

\section{ANÁLISE FACTORIAL DE COMPONENTES PRINCIPAIS}

A análise factorial de componentes principais é um poderoso método estatístico que complementa a estatística descritiva, apresentada no ponto anterior, sobre os clientes de fundos Caixagest. Com esta ferramenta, pode aprofundar-se o estudo do perfil do cliente, realizado apenas para particulares, que constituem a grande maioria dos clientes e dos activos destes fundos.

Sem entrar em explicações demoradas e pormenores mais técnicos sobre o funcionamento estatístico desta análise, que o leitor mais curioso pode facilmente consultar (Pestana e Gageiro, 1998), vamos aplicar a análise factorial de componentes principais aos montantes investidos pelos clientes nos cinco tipos de fundos disponíveis (Liquidez, Aforro, Optimização, Valor Acrescentado e Restantes) e ao montante total aplicado por cada cliente e tentar transformar estas seis variáveis num número adequado de factores que expliquem a sua dispersão.

No Gráfico XXI, apresenta-se o scree plot, que sugere a retenção de quatro componentes, a partir dos quais os valores próprios diminuem 
bastante. Assim sendo, vamos proceder à transformação das seis variáveis analisadas em quatro factores e verificar a relação que se produz.

\section{Gráfico XXI}

SCREE PLOT

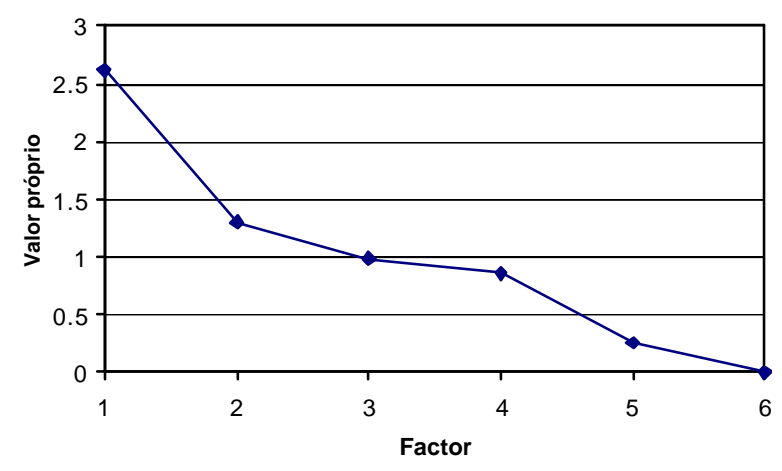

No Quadro VI pode observar-se a variância explicada por cada um dos componentes, bem como a variância total explicada pelos quatro factores retidos (a negrito), que é 95,8\% da variância total. As comunalidades (variância de cada variável explicada pelos componentes retidos) apresentam valores bastante próximos de $100 \%$ para todos os tipos de fundos, com excepção dos de Valor Acrescentado eRestantes, com valores de $88 \%$.

\section{Quadro VI}

FACTORES RETIDOS (a negrito) E VARIÂNCIA TOTAL EXPLICADA

\begin{tabular}{cccc}
\hline Factor & Valor próprio & $\begin{array}{c}\text { \% de variância } \\
\text { explicada }\end{array}$ & $\begin{array}{c}\text { \% de variância } \\
\text { cumulativa }\end{array}$ \\
\hline $\mathbf{1}$ & $\mathbf{2 , 6 1}$ & $\mathbf{3 4 , 2}$ & $\mathbf{3 4 , 2}$ \\
$\mathbf{2}$ & $\mathbf{1 , 2 9}$ & $\mathbf{2 1 , 8}$ & $\mathbf{5 6 , 0}$ \\
$\mathbf{3}$ & $\mathbf{0 , 9 8}$ & $\mathbf{2 0 , 1}$ & $\mathbf{7 6 , 0}$ \\
$\mathbf{4}$ & $\mathbf{0 , 8 6}$ & $\mathbf{1 9 , 8}$ & $\mathbf{9 5 , 8}$ \\
5 & 0,25 & 4,2 & 100,0 \\
6 & 0,00 & 0,0 & 100,0 \\
\hline
\end{tabular}

Os loadings (pesos) relacionam as variáveis originais com cada um dos componentes retidos, sendo que, quanto maior o seu valor, maior a relação. O Quadro VII apresenta a matriz dos loadings, para os componentes retidos, após rotação, através do método Varimax, de modo a escolher 
facilmente o componente ao qual está associada cada variável original. São identificados, a negrito, os factores associados a cada uma das variáveis.

\section{Quadro VII \\ MATRIZ DOS COMPONENTES APÓS ROTAÇÃO}

\begin{tabular}{lcccc}
\hline & \multicolumn{4}{c}{ Componentes } \\
\cline { 2 - 5 } & $\mathbf{1}$ & $\mathbf{2}$ & $\mathbf{3}$ & $\mathbf{4}$ \\
\hline Fundos de Liquidez & 0,10 & 0,00 & $\mathbf{0 , 9 9}$ & $-0,06$ \\
Fundos de Aforro & 0,01 & 0,07 & $-0,05$ & $\mathbf{1 , 0 0}$ \\
Fundos de Optimização & 0,04 & $\mathbf{0 , 9 9}$ & $-0,02$ & 0,05 \\
Fundos de Valor Acrescentado & $\mathbf{0 , 9 1}$ & 0,16 & 0,08 & 0,07 \\
Restantes Fundos & $\mathbf{0 , 9 3}$ & $-0,06$ & 0,08 & $-0,04$ \\
\hline TOTAL & $\mathbf{0 , 5 8}$ & $\mathbf{0 , 5 3}$ & $\mathbf{0 , 4 5}$ & $\mathbf{0 , 4 3}$ \\
\hline
\end{tabular}

A análise factorial de componentes principais reduz para quatro factores as seis variáveis. Os quatro componentes estão directamente relacionados com os montantes investidos em determinados tipos de fundos: factor 1: fundos de Valor Acrescentado e Restantes; factor 2: fundos de Optimização; factor 3: fundos de Liquidez e factor 4: fundos de Aforro; sendo também muito importante a forma bastante homogénea como interagem com o montante total aplicado pelos clientes, o que se torna igualmente importante, pois podemos afirmar que esta variável está relacionada do mesmo modo com todos os componentes retidos, não sendo mais importante para alguns deles, podendo assim ser relegada a importância do seu estudo.

De acordo com o perfil de risco dos vários fundos, o factor 1 representa fundos com risco mais elevado, o factor 2, com risco intermédio, o factor 4 associa-se a um nível de risco baixo e o factor 3 ao nível de risco mais baixo. Com esta associação, estamos perante uma nova possibilidade de análise do perfil de risco do cliente particular de fundos Caixagest na agência de Viseu da CGD, que vem complementar a análise anterior.

Vamos então proceder ao estudo do perfil do cliente segundo os quatro factores agora definidos. Nos gráficos seguintes apresentam-se os desvios aos montantes médios investidos em cada factor, pelos clientes destes fundos: desvios positivos indicam montantes superiores à média e, obviamente, desvios negativos sugerem valores inferiores à média, sendo o desvio tanto maior quanto mais elevado for o seu valor absoluto.

\section{Gráfico XXII}

PERFIL DO CLIENTE SEGUNDO O SEXO E O ESTADO CIVIL 

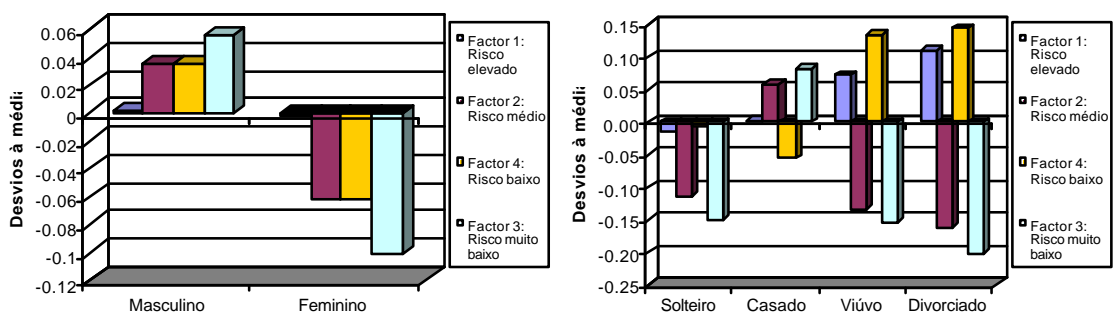

Os montantes aplicados são superiores para o sexo masculino, com excepção dos fundos de alto risco, em que não surgem diferenças nesta variável. As preferências do sexo masculino são maiores para fundos de baixo risco, diminuindo à medida que o risco associado ao investimento aumenta, passando-se o inverso com o sexo feminino. Quanto ao estado civil, tanto viúvos como divorciados investem mais em fundos de risco elevado e de risco baixo, aplicando menos as suas poupanças nos de risco médio e muito baixo, aliás tal como os clientes solteiros, já os casados têm um perfil de investimento completamente oposto. Comparando os dois gráficos verifica-se que as diferenças, para a média, são maiores no estado civil.

\section{Gráfico XXIII}

PERFIL DO CLIENTE SEGUNDO A CLASSE PROFISSIONAL

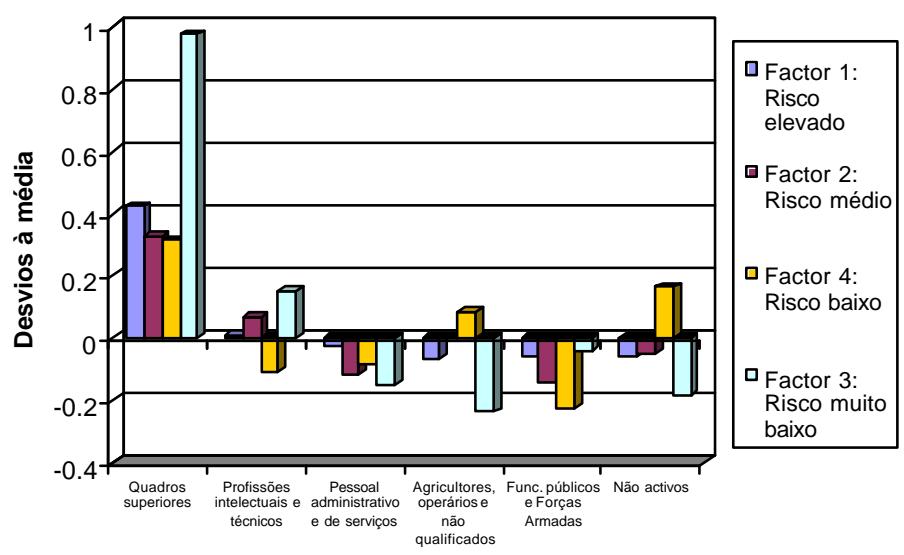

Os Quadros Superiores apresentam um perfil de investimento claramente superior ao das restantes classes, no qual se destacam as aplicações em fundos de risco muito baixo. Nas outras classes profissionais, os investimentos, segundo os factores de risco, são sempre inferiores à média, excepto nas Profissões Intelectuais e Técnicos para os fundos de risco médio e muito baixo e nos Agricultores, Operários e não Qualificados e Não Activos, em que as preferências por fundos com risco baixo se destacam. 


\section{Gráfico XXIV}

PERFIL DO CLIENTE SEGUNDO AS CLASSES ETÁRIAS E A LOCALIZAÇÃO GEOGRÁFICA DA RESIDÊNCIA
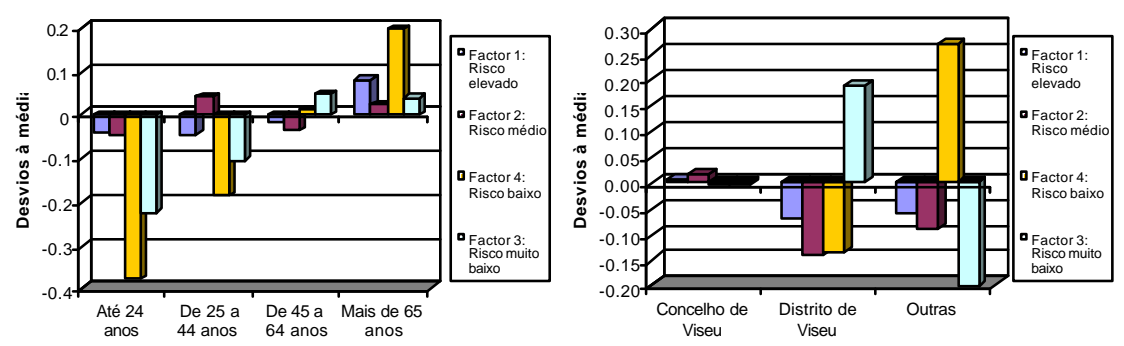

Quanto maiores as idades, maiores são os investimentos em fundos Caixagest, diferenças essas acentuadas para os fundos de risco baixo e muito baixo, não se verificando esta tendência para os fundos de risco médio. Os residentes fora do concelho de Viseu apresentam, de um modo geral, menores valores investidos, excepto no distrito de Viseu (fora do concelho), para os fundos com risco muito baixo e nas outras localizações para os fundos de baixo risco.

\section{Gráfico XXV}

PERFIL DO CLIENTE SEGUNDO OUTRAS CARACTERÍSTICAS

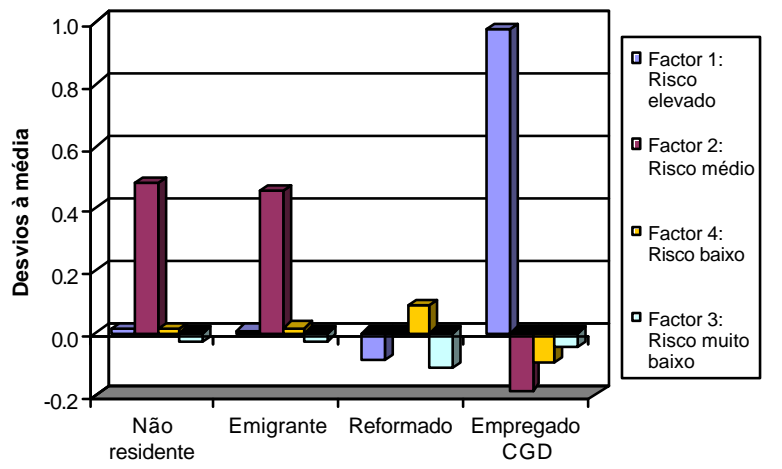

Finalmente, vamos analisar as diferenças relativamente a algumas características especiais dos clientes. Os não residentes e emigrantes preferem investir em fundos de risco médio, os reformados optam mais por fundo com baixo risco e os empregados da CGD têm uma especial apetência por fundos que apresentam risco elevado. 

na agência de Viseu da CGD

\section{CONCLUSÕES}

Este trabalho resulta de um estágio curricular da licenciatura em Gestão e Desenvolvimento Social desenvolvido na agência de Viseu da CGD, crucial por ter originado a recolha da grande quantidade de dados necessários, que teve lugar no decorrer do mês de Janeiro de 2000.

É de salientar, desde já, a importante colaboração que a Universidade Católica Portuguesa, nomeadamente o seu Pólo de Viseu, mantém com tão prestigiada instituição bancária, que muito nos releva e que permite o desenvolvimento de colaborações como a que aqui apresentamos. Não queremos, por esse motivo, deixar de prestar um agradecimento especial à agência de Viseu e à Direcção Regional da CGD.

Com este trabalho conseguimos desenvolver uma ampla caracterização do perfil do cliente de fundos de investimento mobiliário Caixagest, recorrendo a técnicas de estatística descritiva e à análise factorial de componentes principais.

\section{NOTAS}

${ }^{1}$ Cf. CAIXAGEST, TÉCNICAS DE GESTÃO DE FUNDOS, S.A. (1998). Relatório e Contas - 1998, p. 15.

${ }^{2}$ Idem, p. 17.

${ }^{3}$ Uma análise mais profunda da rentabilidade, em função destes dois importantes parâmetros, pode ser facilmente executada no site da Internet da Caixagest: http://caixagest2.tinta.pt/caixagest.

${ }^{4}$ ENCICLOPÉDIA MIRADOR INTERNACIONAL (1981), Encyclopeadia Britannica do Brasil, Ed. Publicações Ld. a, São Paulo, p. 8810.

${ }^{5}$ MURTEIRA, Bento J.F. (1993), Análise exploratória de Dados - Estatística Descritiva, Ed. McGraw-Hill de Portugal, Lisboa, p. 101. 


\section{ANEXOS}

Quadro A.1

RESUMO DAS CARACTERÍSTICAS DOS FUNDOS CAIXAGEST

\begin{tabular}{|c|c|c|c|c|c|c|c|}
\hline $\begin{array}{l}\text { Tipo de } \\
\text { Fundo }\end{array}$ & Fundos & $\begin{array}{c}\text { Subscrição inicial } \\
(€ / \text { contos })\end{array}$ & $\begin{array}{l}\text { Sub. posterior } \\
(€ / \text { contos })\end{array}$ & $\begin{array}{c}\text { Comissão de } \\
\text { subscrição / resgate }\end{array}$ & $\begin{array}{c}\text { Dias de } \\
\text { pré-aviso }\end{array}$ & Tipo de fundo & $\begin{array}{c}\text { Prazo } \\
\text { recomendado }\end{array}$ \\
\hline \multirow{3}{*}{ Liquidez } & Curto Prazo & $500 € / 100 \mathrm{c}$ & --------- & $0 \% / 0 \% *$ & 1 & & \multirow{3}{*}{$<6$ meses } \\
\hline & Tesouraria & $10000 € / 2000 \mathrm{c}$ & $2500 € / 500 \mathrm{c}$. & $0 \% / 0 \% *$ & 1 & & \\
\hline & Moeda & $250000 € / 50000 \mathrm{c}$. & --------- & $0 \% / 0 \% *$ & 1 & & \\
\hline \multirow{2}{*}{ Aforro } & Renda Mensal & $5000 € / 1000 \mathrm{c}$. & $100 € / 20 \mathrm{c}$ & $0 \% / 1,5 \%:<12 \mathrm{~m}$ & 2 & & \multirow{2}{*}{$>1$ ano } \\
\hline & Rendimento & $2500 € / 500 \mathrm{c}$ & $500 € / 100 \mathrm{c}$. & $0 \% / 1,5 \%:<3 \mathrm{~m} \mathrm{1 \%}: 3-6 \mathrm{~m}$ & 2 & Indexadas & \\
\hline \multirow{3}{*}{ Optimização } & Multivalor & $2500 € / 500 \mathrm{c}$. & $500 € / 100 \mathrm{c}$. & $0 \% / 1 \%:<3 \mathrm{~m} 0,5 \%: 3-6 \mathrm{~m}$ & 3 & Misto & $>1$ ano \\
\hline & Investimento & $2500 € / 500 \mathrm{c}$. & $500 € / 100 \mathrm{c}$. & $0 \% / 1 \%:<12 \mathrm{~m}$ & 3 & Fundos Caixagest & $>2$ anos \\
\hline & Maxivalor & $2500 € / 500 \mathrm{c}$. & $500 € / 100 \mathrm{c}$. & $0 \% / 1 \%:<3 \mathrm{~m} \mathrm{0,5 \% :3-6m}$ & 3 & Misto & $>2$ anos \\
\hline \multirow{5}{*}{$\begin{array}{l}\text { Valor } \\
\text { Acrescentado }\end{array}$} & Renda Acumulada & $500 € / 100 \mathrm{c}$ & -------- & $0 \% / 1 \%<12 \mathrm{~m}$ & 2 & Obrigaç. Tx Fixa & $>2$ anos \\
\hline & Multidivisa & $500 € / 100 \mathrm{c}$. & --------- & $0 \% / 0 \% *$ & 1 & Tesour. Internac. & $>6$ meses \\
\hline & Internacional & $500 € / 100 \mathrm{c}$. & -------- & $0 \% / 1,5 \%:<12 \mathrm{~m}$ & 3 & Acções Europeias & $>2$ anos \\
\hline & Valorização & $500 € / 100 \mathrm{c}$ & --------- & $0 \% / 1,5 \%:<12 \mathrm{~m}$ & 3 & Acções Nacionais & $>2$ anos \\
\hline & PPA Val. Fiscal & $500 € / 100 \mathrm{c}$. & --------- & $0 \%$ / Variável $0 \%$ a $6 \%$ & 5 & Acções PTE & $>6$ anos \\
\hline Gestão & Taxa Fixa & $500 € / 100 \mathrm{c}$ & -------- & $1 \% / 2 \%$ & 2 & Obrigaç. Tx Fixa & $>3$ anos \\
\hline Agressiva & Acções Portugal & $500 € / 100 \mathrm{c}$. & ---------- & $5 \% / 3 \%$ & 3 & Acções Nacionais & $>3$ anos \\
\hline
\end{tabular}

* Investimentos por prazo inferior a 7 dias são resgatados ao valor mais baixo entre o valor de subscrição e o valor de resgate

** Benefício Fiscal do PPA: dedução à colecta de 7,5\% das entregas anuais com um máximo de 37,5 c. por sujeito passivo ou 75 c. por casal 
Quadro A.1 (continuação)

\begin{tabular}{|c|c|c|c|c|c|c|}
\hline \multicolumn{7}{|c|}{ Agrupamento de fundos Caixagest Gestão } \\
\hline Agrupamento de Fundos & $\begin{array}{c}\text { Subscrição Inicial } \\
(€ / \text { contos })\end{array}$ & $\begin{array}{c}\text { Subscr. posterior } \\
(€ / \text { contos })\end{array}$ & $\begin{array}{c}\text { Comissão de } \\
\text { subscrição / resgate }\end{array}$ & $\begin{array}{c}\text { Dias de } \\
\text { pré-aviso }\end{array}$ & Tipo de Fundo & $\begin{array}{c}\text { Prazo } \\
\text { recomendado }\end{array}$ \\
\hline Caixagest Gestão & $100000 € / 20000 \mathrm{c}$. & $5000 € / 1000 \mathrm{c}$ & $0 \% / 1,5 \%:<24 \mathrm{~m}$ & sub fundo & Agrupamento & $>2$ anos \\
\hline \multicolumn{7}{|l|}{ Sub Fundos } \\
\hline Gestão Monetária & $5000 € / 1000 \mathrm{c}$. & & $-------/ 0 \%$ *** & 1 & Tesouraria Nacional & --------- \\
\hline Gestão Eurobrigações & $5000 € / 1000 \mathrm{c}$ & & ------ / $0 \% * * *$ & 4 & Obrigações Taxa Fixa & --------- \\
\hline Gestão Cambial & $5000 € / 1000 \mathrm{c}$. & & $------/ 0 \% * * *$ & 1 & Divisas & --------- \\
\hline Gestão Interobrigações & $5000 € / 1000 \mathrm{c}$. & & $----/ 0 \% * * *$ & 5 & Obrigações Taxa Fixa & \\
\hline Gestão Euroacções & $5000 € / 1000 \mathrm{c}$. & & ------- / 0\% *** & 5 & Acções Europeias & --------- \\
\hline Gestão Lusoacções & $5000 € / 1000 \mathrm{c}$. & & $------/ 0 \% * * *$ & 4 & Acções Nacionais & --------- \\
\hline \multicolumn{7}{|c|}{ Fundos off-shore Caixa Luxemburgo } \\
\hline Caixa Tesouraria & 2500 & & $0 \% / 0 \% *$ & 2 & Tesouraria Nacional & $<6$ meses \\
\hline Caixa Obrigações & 2500 & & $0 \% / 1 \%:<6 \mathrm{~m} 0,5 \%: 6-12 \mathrm{~m}$ & 4 & Obrigações Taxa Fixa & $>2$ anos \\
\hline Caixa Europa Acções & 2500 & & $0 \% / 1,5 \%:<12 \mathrm{~m}$ & 4 & Acções Europeias & $>2$ anos \\
\hline Caixa Portugal Acções & 2500 & & $0 \% / 1,5 \%:<12 \mathrm{~m}$ & 4 & Acções Nacionais & $>2$ anos \\
\hline
\end{tabular}

* Investimentos por prazo inferior a 7 dias são resgatados ao valor mais baixo entre o valor de subscrição e o valor de resgate

*** Comissão de transferência

Fonte: Adaptado de Resumo de Características dos fundos Caixagest; Site na Internet: http://caixagest2.tinta.pt/caixagest. 


\section{Quadro A.2 \\ AGRUPAMENTO DAS PROFISSÕES DOS CLIENTES CAIXAGEST SEGUNDO A CLASSIFICAÇÃO NACIONAL DE PROFISSÕES (1994)}

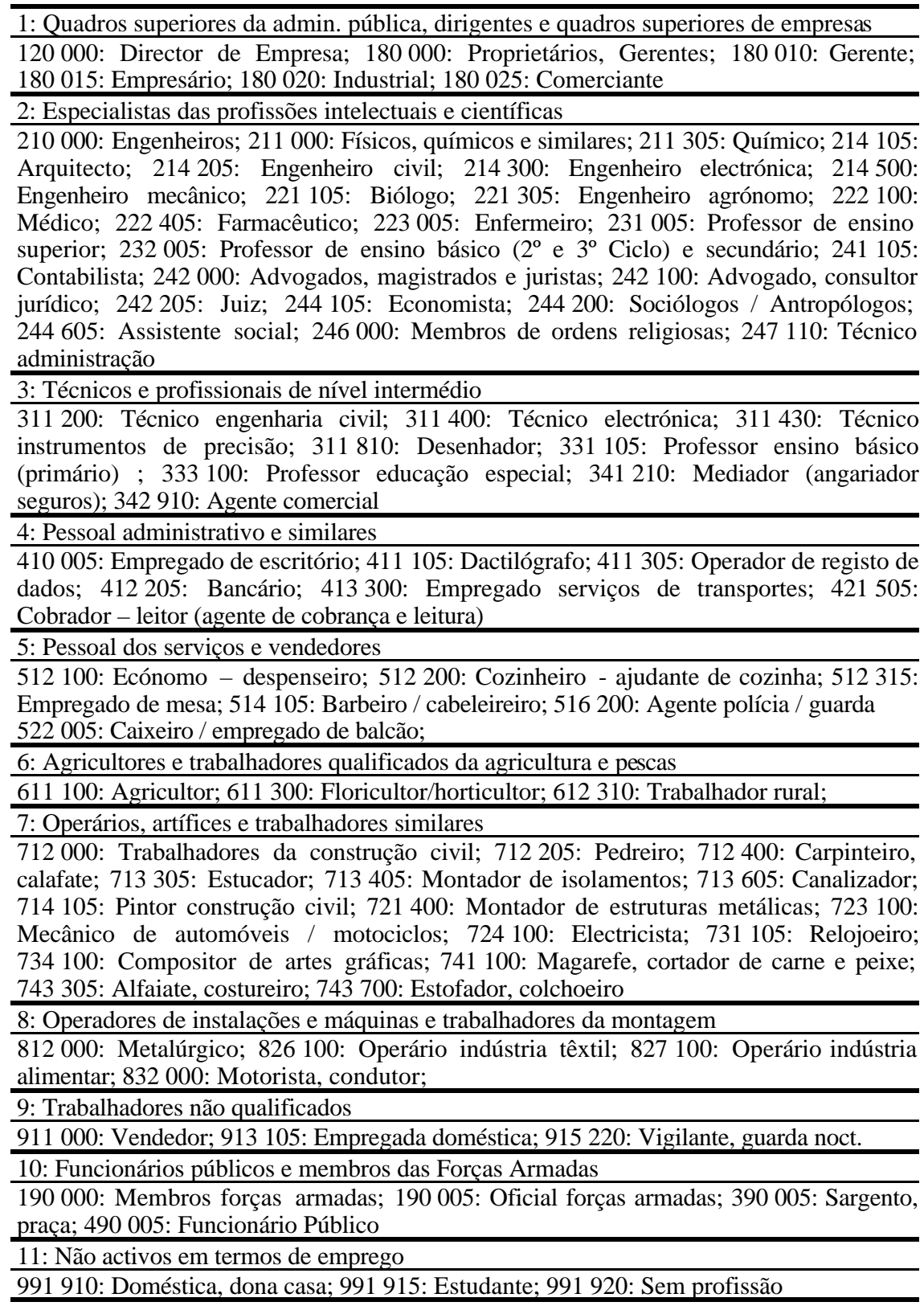




\section{Quadro A.3}

AGRUPAMENTO DAS EMPRESAS CLIENTES CAIXAGEST, POR SECTORES DE ACTIVIDADE, SEGUNDO A CLASSIFICAÇÃO DE ACTIVIDADE ECONÓMICA

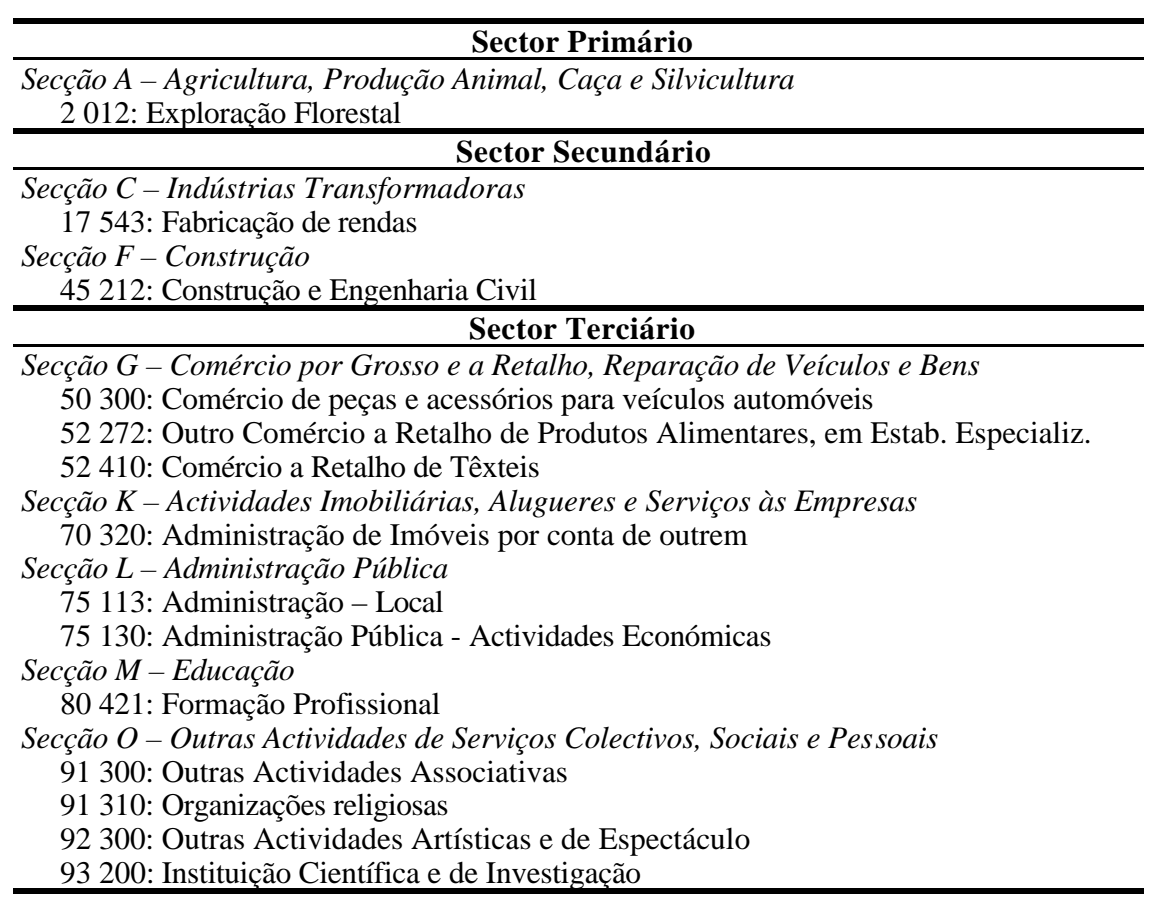




\section{BIBLIOGRAFIA}

CGD - Caixa Geral de Depósitos (1997), Relatório de Contas 1997, Ed. Caixa Geral de Depósitos, Lisboa.

CGD - Caixa Geral de Depósitos (1998), Relatório de Contas 1998, Ed. Caixa Geral de Depósitos, Lisboa.

CAIXAGEST - Técnicas de Gestão de Fundos, S.A. (1998), Relatório e Contas - 1998, Ed. Caixa Geral de Depósitos, Lisboa.

GUIMARÃES, R. C.; CABRAL, J. A. Sarsfield (1998), Estatística, Ed. Revista, Ed. McGraw-Hill, Lisboa.

IEFP - INSTITUTO DO EMPREGO E FORMAÇÃO PROFISSIONAL (1994), Classificação Nacional de Profissões, Edição: Instituto do Emprego e Formação Profissional, Ministério do Emprego e Segurança Social, Lisboa.

MURTEIRA, Bento J. F. (1993), Análise exploratória de Dados - Estatística Descritiva, Ed. McGraw-Hill de Portugal, Lisboa.

PESTANA, M.H.; GAGEIRO, J. N. (1998), Análise de Dados para Ciências Sociais - A Complementaridade do SPSS, Edições Sílabo, Lisboa

REIS, E.; MELO, P.; ANDRADE, R.; CALAPEZ, T. (1996), Estatística Aplicada, Edições Sílabo, Lisboa. 